\title{
Helping Egyptian women achieve optimal birth spacing intervals through fostering linkages between family planning and maternal/ child health services
}

Nahla G. Abdel-Tawab

Population Council

Sarah Loza

Amal Zaki

Follow this and additional works at: https://knowledgecommons.popcouncil.org/departments_sbsr-rh

Part of the Demography, Population, and Ecology Commons, Health Services Research Commons, International Public Health Commons, and the Maternal and Child Health Commons How does access to this work benefit you? Let us know!

\section{Recommended Citation}

Abdel-Tawab, Nahla G., Sarah Loza, and Amal Zaki. 2008. "Helping Egyptian women achieve optimal birth spacing intervals through fostering linkages between family planning and maternal/child health services," FRONTIERS Final Report. Washington, DC: Population Council. 


\section{Helping Egyptian women achieve optimal birth spacing intervals through fostering linkages between family planning and maternal/child health services}

Frontiers in Reproductive Health Program, Population Council

Dr. Nahla Abdel-Tawab

Social Planning, Analysis and Administration Consultants

Dr. Sarah Loza

Population and Family Planning Sector, Ministry of Health and Population Dr. Amal Zaki

September 2008

This study was made possible by the generous support of the American people through the United States Agency for International Development (USAID) under the terms of Cooperative Agreement Number HRN-A-00-98-00012-00,

Subagreement AI05.38A and In-house project 5800 53094. The contents are the responsibility of FRONTIERS and do not necessarily reflect the views of USAID or the United States Government.
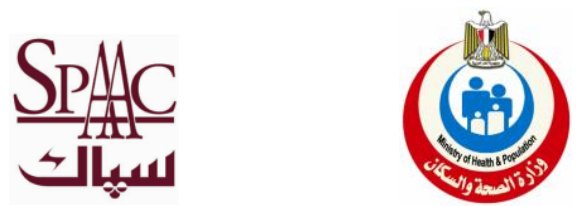


\section{EXECUTIVE SUMMARY}

One major challenge facing policy-makers is how to support women in achieving healthier birth intervals, i.e. a birth to conception interval of at least two years. To respond to this challenge, the Population Council's USAID-funded Frontiers in Reproductive Health (FRONTIERS) program, in collaboration with the Egyptian Ministry of Health and Population (MOHP) and the NGO 'Social Planning, Analysis and Administration Consultants' (SPAAC), conducted an operations research study to measure the acceptability and effectiveness of two birth spacing message models. For Model I (health services model), birth spacing messages were communicated through services by health workers to women during prenatal and postpartum periods. Model II (community awareness model), provided this service plus an awareness raising component that targeted men through training community influentials to communicate messages.

The study used an experimental design in six health districts, three from each governorate of Assiut and Sohag in Upper Egypt. One district in each governorate was randomly assigned to implement Model I, Model II or to serve as a control site by providing standard care only. Sources of data for this study included: (1) exit and home interviews with low parity pregnant women at 4 months and 10-11 months postpartum (a total of 1,416 women); (2) structured interviews with physicians, nurses and family planning outreach workers; (3) in-depth interviews with local MOHP managers and supervisors; (4) focus group discussions (FGDs) with community influentials; (5) FGDs with husbands of low parity women; and (6) service statistics on utilization of $\mathrm{MCH}$ and family planning services.

Providing birth spacing messages to low parity women during antenatal and postpartum care and also to husbands through community awareness activities was feasible and acceptable. Both models proved effective in changing women's knowledge and attitudes towards birth spacing and in enhancing use of contraception at 10-11 months postpartum, by 48 percent among Model I mothers and 43 percent among Model II mothers, compared with 31 percent among control group mothers. Over the postpartum period, women in the two intervention groups used contraception more consistently than women in the control group - median duration of protection against pregnancy was 6.8 months for Model I mothers, 4.5 months for Model II mothers and 2.9 months for control group mothers). Both intervention models were associated with an increased utilization of services, especially family planning services, by women who only had one child (36 percent increase in Model I clinics, 47 percent increase in Model II clinics and 3.2 percent in control clinics). However, a fear of contraceptive side-effects continues to be a major concern among women and men in all groups and is an obstacle in achieving healthy birth intervals.

The study results have been widely disseminated in the two study governorates and have been shared with senior MOHP officials in Population and Family Planning Sector and the Maternal and Child Health Sector, and with CAs, donors and researchers. Birth spacing messages have been integrated into service delivery guidelines for antenatal and postpartum care. IEC materials on birth spacing and postpartum use of contraception, including correct use of LAM, have been produced and widely disseminated. Discussions are underway with MOHP officials to enhance the effectiveness of the day 40 postpartum visit, by providing more $\mathrm{MCH}$ services along FP services on that visit. 


\section{TABLE OF CONTENTS}

Executive summary Error! Bookmark not defined.

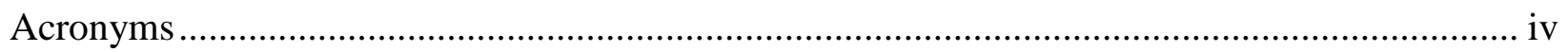

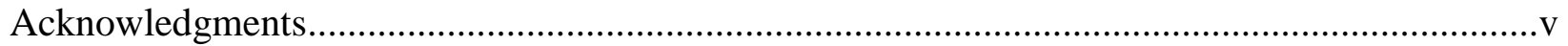

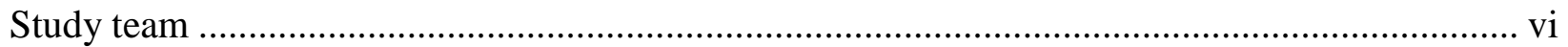

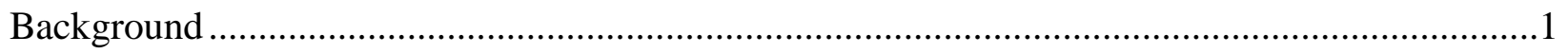

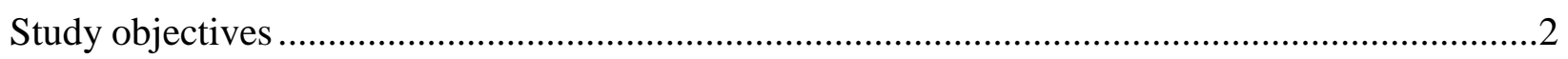

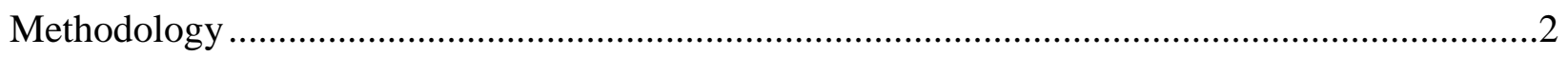

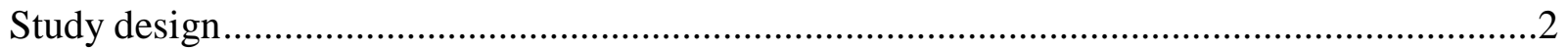

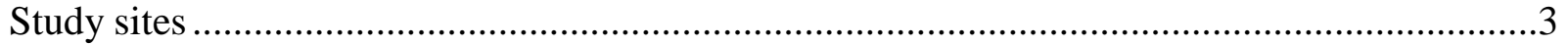

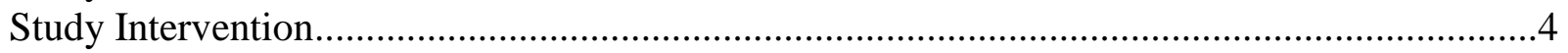

Birth spacing message protocol ...............................................................................

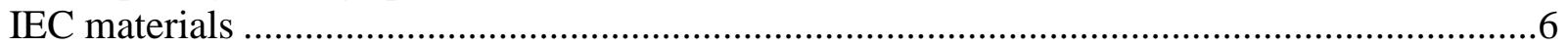

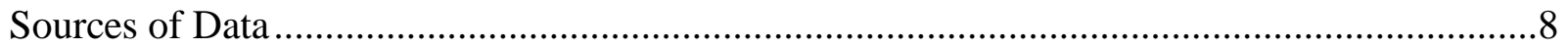

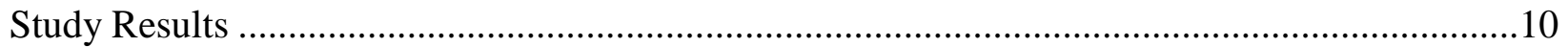

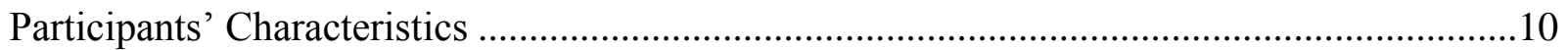

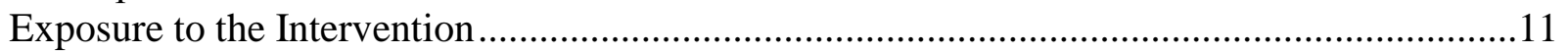

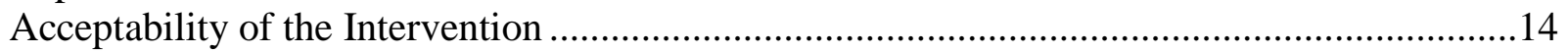

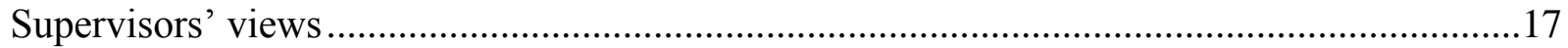

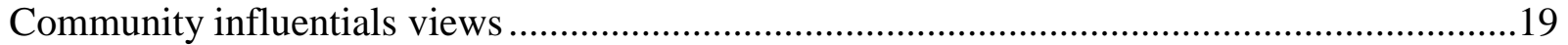

Impact of the Intervention on Knowledge, Attitudes and Behaviors .................................20

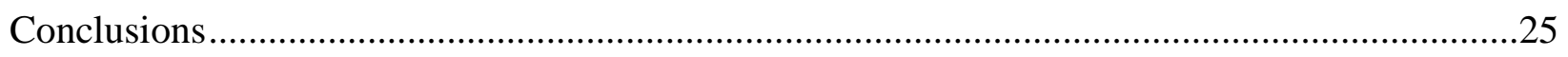

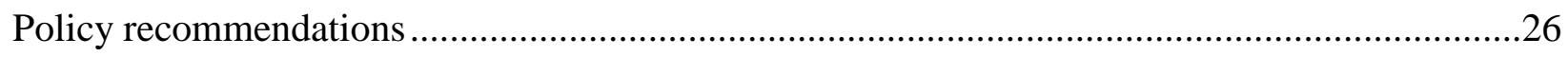

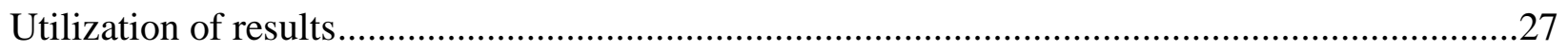

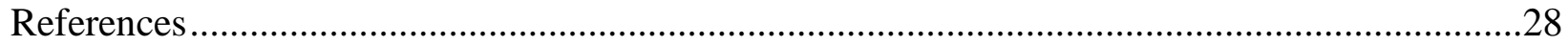

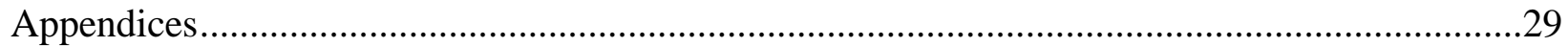




\section{LIST OF TABLES}

Table 1: Distribution of districts and clinics over the three study arms and population size of each district (2004)

Table 2: Different types of training that were offered in the study

Table 3: Number of recruited women at each phase of data collection .......................................8

Table 4: Percent distribution of women by time of second home interview ...............................9

Table 5: Distribution of managers and supervisors who participated in in-depth interviews

Table 6: Demographic characteristics of pregnant women who were enrolled in the study (by study group)

Table 7: Percent distribution of providers by occupation and duration of work at study clinic.....

Table 8: Low parity women's reports on services received at prenatal care, postpartum and extended postpartum period

Table 9: Percent distribution of low parity women by acceptance of birth spacing discussions during antenatal care

Table 10: Low parity women's views on quality of prenatal and postpartum care services

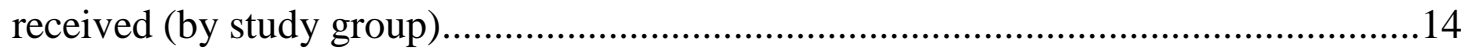

Table 11 : Service providers' exposure to the intervention (by occupation)..... .16

Table 12: Service providers' reports on counseling topics provided during antenatal care (by occupational group)

Table 13: Service providers' reports on services provided during postpartum period (by occupational group).

Table 14: Percentage distribution of health providers by views on sustainability of the intervention

Table 15: Percent distribution of birth spacing attitudes and intentions (by study group)

Table 16 : Contraceptive use at 4 months postpartum and knowledge of correct use of LAM (by study group)

Table 17: Percent distribution of contraceptive use at 10-12 months postpartum (by study group)

Table 18: Percent distribution of reported husband acceptance of birth spacing by women in the three study groups 


\section{ACRONYMS}

CAs Cooperating Agencies

FGDs Focus Group Discussions

FP Family Planning

$\mathrm{MCH} \quad$ Maternal and Child Health

MOHP Ministry of Health \& Population

IEC Information, Education and Communication

SPAAC Social Planning, Analysis and Administration Consultants

USAID United States Agency for International Development 


\section{ACKNOWLEDGMENTS}

We wish to thank all the individuals and institutions that have contributed to the successful completion of this project. Dr. Esmat Mansour, former First Undersecretary for Maternal and Child Health Services and Dr. Yehia El-Hadidi, former First Undersecretary for Population and Family Planning Sector, gave their full support to this project throughout its implementation. Dr. Khaled Nasr, current Undersecretary for Maternal and Child Health and Dr. Hassan El-Gebaly, Head of Population and Family Planning sector, have shown keen interest in the study and in utilization of its results. The technical support we received from colleagues at the two sectors in training of trainers and in monitoring the intervention is deeply appreciated.

The enthusiasm and commitment of MOHP undersecretaries in Assiut and Sohag governorates and Family Planning and $\mathrm{MCH}$ managers and supervisors in the two governorates were instrumental to the successful implementation of the intervention. The doctors, nurses and Raidat Rifyat working in the study clinics are gratefully acknowledged for their cooperativeness in implementing the intervention.

We also wish to express our appreciation to the data collection team that successfully completed interviews with pregnant and postpartum women, husbands, health care providers, supervisors and community influentials. Needless to say those interviews would not have been possible without the cooperativeness and candidness of all those groups.

The Communication for Healthy Living (CHL) Project is acknowledged for its support in developing and printing the Birth Spacing flier. We are also grateful to our colleagues at the FRONTIERS Program and SPAAC for their dedication and hard work throughout the implementation of the study. Last but not least, we wish to thank USAID/ Washington for funding this study and USAID Mission in Egypt for their continued support. 


\section{STUDY TEAM}

\section{FRONTIERS Program}

Dr. Nahla Abdel-Tawab

Dr. Hala Youssef

Ms. Magda Fayek

Ms. Gihan Hosny

SPAAC Team

Dr. Sarah Loza

Dr. Iman Soliman

Ms. Rosa Abdel-Malek

Ms. Sabah El-Werdany

Ms. Iman Badr

\section{MOHP Team}

Population and FP sector

Dr. Hassan El-Gebaly

Dr. Yahia El-Hadidi

Dr. Amal Zaki

\section{Assiut Governorate}

Dr. Ahmed Abdel-Moneim

Dr. Feryal Ibrahim

Dr. Omayma Youssef

Dr. Ahmed Galal

Dr. Ahmed Anwar

Dr. Abdel-Hafeez Hassan

Dr. Gamal Abdel-Aleem

\section{Data Collection Team}

Ms. Marwa Zein El-Abedeen

Ms. Heba Dardeery

Ms. Doa'a Hammam

Ms. Mohamed Moustafa
Program Associate

Program Officer

Program Administrator

Senior Administrative and Publications Assistant

President

Vice President

Computer Specialist

Senior Researcher

Researcher

\section{Maternal Child Health Sector}

Dr. Esmat Mansour

Dr. Khaled Nasr

Dr. Salwa Farag

Dr. Ahmed Metwally

\section{Sohag Governorate}

Dr. Mohamed Abdel-Aal

Dr. Fadel Aly

Dr. Yousry Mabrouk

Dr. Sonia Fouad

Dr. Hani Lotfy

Dr. Gamal Salman

Dr. Khairy Bekhit

Ms. Ro'yat Abdellah

Ms. Wala'a Aboul Ezz

Ms. Hameeda Mahfouz

Ms. Mohamed Darweesh 


\section{BACKGROUND}

Based on recommendations of a WHO technical consultation and findings of several studies, a birth to conception interval of at least two years has been recommended to reduce the risk of adverse maternal, perinatal and infant outcomes (World Health Organization, 2006). Research suggests that a 3-5 year inter-pregnancy interval is associated with a lower risk of miscarriage, newborn death, and maternal death. Additional to these direct health benefits for mother and child, birth spacing has social benefits such as increased savings, less stress on the mother and more time for the couple to engage in other activities (Setty-Venugopal \& Upadhyay, 2002).

In general, women in developing countries have shorter birth intervals than they would prefer. Secondary analysis of data from the Egypt interim Demographic and Health Survey has shown that more than half of all non-first births occurred less than three years after a previous birth (Zaky, 2006), while one in five births took place less than two years after a previous birth. Birth intervals tend to be shorter among younger women (15-19 years old) and among those who live in rural areas, especially in rural Upper Egypt (El-Zanaty \& Way, 2006).

The main reason for short birth intervals is that many women in developing countries do not use contraception after birth and therefore are likely to become pregnant once fecundity returns. An analysis of DHS data from more than 20 countries showed that although very few postpartum women want another child within two years, only 40 percent are using family planning in the extended postpartum period (Ross \& Winfrey, 2001). Many women do not use contraception during this period because they are not aware that they could become pregnant while breastfeeding. Others are afraid of the effects of contraception on their health or the health of their breastfed infant. Husbands and mothers-in-law sometimes also put pressure on women to get pregnant soon, and to have a male child.

One major challenge facing policy-makers and program managers is how to support women in achieving healthier birth intervals. To respond to this need, the Population Council's USAIDfunded Frontiers in Reproductive Health (FRONTIERS) program designed an operations research (OR) study to measure acceptability and effectiveness of two models of providing birth spacing messages to women and husbands in Egypt. The first model involved provision of birth spacing messages through health services for women during their prenatal and postpartum periods. The second model involved communicating the same messages plus an information, education and communication (IEC) component targeting husbands through community influentials.

This OR study was implemented collaboratively by the FRONTIERS Program, the Ministry of Health and Population (MOHP) Maternal and Child Health and Population and Family Planning Sectors and the NGO Social Planning, Analysis and Administration Consultants (SPAAC), with funding from USAID. The intervention was implemented by MOHP with technical assistance from FRONTIERS, and the research component was implemented by SPAAC. Implementation of this OR study has proceeded in four phases. During phase I a diagnostic study identified components of the intervention and developed relevant birth spacing messages. Phase II included the development and implementation of the intervention and phases III and IV involved evaluation of the intervention and dissemination and utilization of results. 


\section{STUDY OBJECTIVES}

The overall goal of this OR study was to help more women achieve healthier birth intervals with the ultimate goal of ensuring better health and well-being for mothers and children. Specific objectives of the study were:

1. To measure the acceptability of two birth spacing messages models (a health services model that targets women only, and a community awareness model that targets women and husbands through community influentials);

2. To compare the effectiveness of the two models in improving women's knowledge of optimal birth spacing intervals (OBSI), correct use of Lactational Amenorrhea Method (LAM), and postpartum use of contraceptives;

3. To assess the impact of the two models on improving husbands' knowledge and attitudes about birth spacing and postpartum use of contraception; and

4. To compare the impact of the two models on the utilization of maternal and child health $(\mathrm{MCH})$ and family planning $(\mathrm{FP})$ services.

\section{METHODOLOGY}

\section{Study design}

For objective \# 1, the study used a cross-sectional descriptive design. Acceptability was assessed among health care providers, supervisors, women, husbands and community leaders who had been exposed to the intervention.

For objective \# 2, the study used a post-test panel design with a non-equivalent control group. Clinics that participated in the study were divided into three groups. Group I applied the health services model. group II applied the community awareness model with the IEC component, and a third group of clinics served as a control group, and applied the standard care and IEC activities for women and men.

A cohort of pregnant women in their third trimester, who visited these three sets of clinics for prenatal care services during the enrollment period, were followed up through home interviews at 4 months and 10-12 months postpartum. These visits and interviews were conducted to ascertain any differences in birth spacing intentions and postpartum contraceptive use that may have resulted from the type of care received at the clinic.

For objective \# 3, i.e. husbands' knowledge and attitudes, the study used qualitative methods to examine differences across the participants in the three study groups.

Objective \# 4 included a time series design, used whereby service statistics for each of the three sets of clinics were reviewed for three months prior to the intervention (October - December 2005), and then three months post-intervention (March - May 2007). The following service 
statistics were collected: total number of FP clients who received a contraceptive method, total number of FP clients with one child, total number of new antenatal care clients.

\section{Study sites}

The OR study was implemented in two of Upper Egypt governorates (Assiut and Sohag), located about 234 miles and 306 miles south of Cairo, respectively. These two governorates have relatively low contraceptive prevalence rates compared to other governorates in the country (39\% for Sohag and $45 \%$ for Assiut as opposed to a $58 \%$ national rate) and have low scores on most socio-demographic and health indicators. Levels of antenatal care services use are almost equal in the two governorates (50\% in Assiut and 45\% in Sohag) (El-Zanaty, personal communication).

Figure 1: Map of Egypt

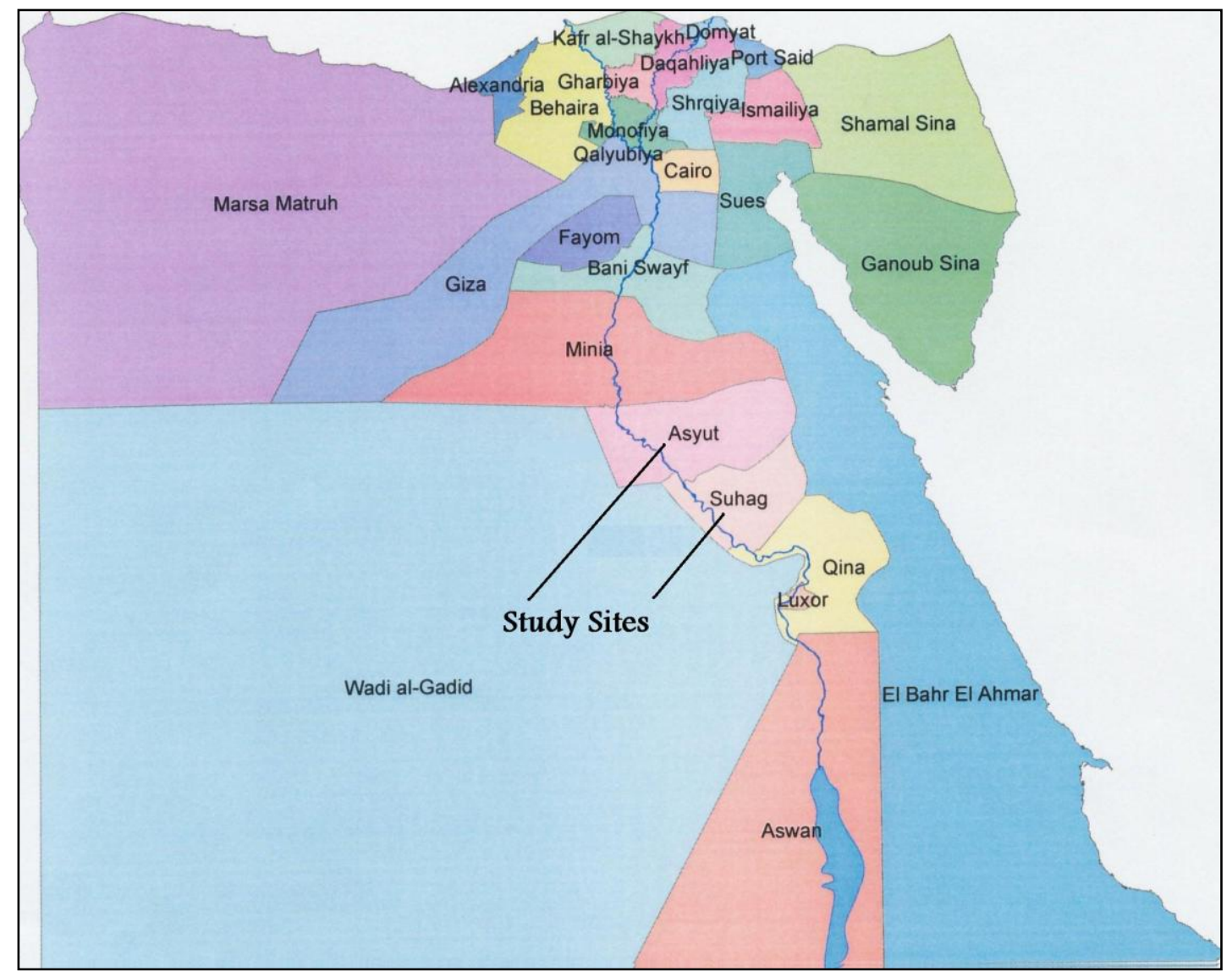

The study used a nested design. Within each of the governorates three health districts were selected, in consultation with MOHP supervisors in each governorate. Districts were matched based on socio-economic characteristics, birth rates and contraceptive prevalence rates. In each governorate, one district was randomly assigned to receive the health services model; a second received the community awareness model and a third served as control. Within each health district, five rural MOHP clinics were selected, yielding a total of 30 clinics (10 in each study arm). Clinics with a minimum of 30 prenatal care visits per month were given priority of inclusion in the study. 
Table 1: Distribution of districts and clinics over the three study arms and population size of each district (2004)

\begin{tabular}{|l|c|c|c|}
\hline & Health services model & $\begin{array}{c}\text { Community } \\
\text { awareness model }\end{array}$ & Control group \\
\hline Assiut governorate & Markaz Assiut district & $\begin{array}{c}\text { El-Quseya district } \\
(5 \text { clinics })\end{array}$ & $\begin{array}{c}\text { Abnoub district } \\
(5 \text { clinics })\end{array}$ \\
Population size & (5 clinics) & 349,105 & 300,227 \\
\hline Sohag governorate & 386,227 & Tahta district & Markaz Sohag district \\
(5ema district & (5 clinics) $)$ \\
Population size & $(5$ clinics) & 365,279 & 586,421 \\
\hline Total & 324,904 & 10 clinics & 10 clinics \\
\hline
\end{tabular}

\section{Study Intervention}

\section{Diagnostic study}

A diagnostic study was undertaken by Social Planning, Analysis and Administration Consultants (SPAAC) to assist in the identification of the intervention components and in selecting the most relevant birth spacing messages. The study investigated knowledge and attitudes about birth spacing among low-parity women, their husbands, community influentials, and health care providers. The study also examined existing services and opportunities within MCH and FP programs that could potentially promote healthier birth intervals among the governorate's women.

The study was conducted in five rural MOHP facilities and included a number of methodologies: structured interviews with clinic staff (physicians, nurses, and Raedat Rifiyat (RRs)); focus group discussions (FGDs) with pregnant and postpartum women with two or fewer living children; FGDs with married men with two or fewer living children, and; FGDs with influential members and opinion leaders in the above communities (Loza, 2005).

Results from the Diagnostic Study revealed a general acceptance of birth spacing for 2-3 years from birth to conception (but not 4-5 years) among men and women. It was also clear that women and men had limited knowledge of the adverse effects associated with short birth intervals, and failure to achieve desired birth intervals was often due to experience of contraceptive side-effects or concerns about potential side-effects. Most commonly mentioned side-effects of concern were bleeding associated with the IUD, weakness and water retention associated with the pills, and concern about the effects of injectables on future fertility. Incorrect use of LAM was found to be another key reason underlying women's failure to achieve birth spacing. In general most participants (women, husbands, health providers and community influentials) were under the impression that breastfeeding was effective as a method of contraception as long as the woman's menstrual period had not returned after delivery. One barrier mentioned to sometimes hinder the achievement of a desired birth interval was the possible pressure from the husband and/or mother-in-law to have another child soon after giving birth to a daughter, as sons are more desired among many Egyptian families.

The diagnostic study revealed several missed opportunities for providing birth spacing messages and information on postpartum contraception to women and their husbands. The first opportunity 
is during antenatal care, especially visits during the third trimester, when women go to the clinic to receive Tetanus Toxoid but rarely received any information on birth spacing or postpartum contraception. Another opportunity is postpartum home visits, which are meant to involve the $\mathrm{MCH}$ nurse and RR, but have lacked coordination in actual roll-out. The day 40 visit to the clinic is severely underutilized, although it offers a good opportunity for providing birth spacing messages along with messages and services for the mother and newborn. Lastly, husbands of postpartum women play a key role in the decision to space or not to space births and hence should be reached with appropriate messages to positively influence this dynamic.

Findings of the diagnostic study were shared with senior MOH officials and an intervention that maximizes opportunities in antenatal and postpartum care was developed in collaboration with officials of the Population and Family Planning Sector and the Maternal and Child Health Sector.

\section{Components of the intervention}

An intervention was developed jointly with Ministry of Health and Population (MOHP) officials at the central and governorate levels to target pregnant and post partum women and husbands. Main components of the intervention were as follows: (1) a protocol for birth spacing messages to pregnant and postpartum women through antenatal care and postpartum care, (2) awarenessraising activities for men through community seminars, one-to-one meetings, informal discussions, and (3) IEC materials for women, men and health care providers.

\section{Birth spacing message protocol}

The protocol capitalizes on available resources of MOHP and takes advantage of the different encounters that women have with the health care system during pregnancy and postpartum period. Components of the protocol were as follows:

- Birth spacing messages for low parity pregnant women during prenatal care visits in the third trimester. Messages included duration of healthy birth intervals, advantages of birth spacing, effective use of LAM and importance of the $40^{\text {th }}$ day postpartum visit.

- Home visits to postpartum women by the MCH nurse and the $R R$ on day 2, day 4, day 7, day 21 and day 30-35. It should be noted that existing MOHP protocols require five postpartum home visits by the MCH nurse and one visit by the RR before the $40^{\text {th }}$ day postpartum. During those visits the nurse checked on the health of the mother and the newborn and looked for warning signs while the $R R$ gave health education and birth spacing messages. ${ }^{1}$

- Comprehensive MCH and FP services to the woman and newborn on day 40 postpartum, including a physical assessment of the mother and newborn, ascertaining infant immunization status, health education on breastfeeding, nutrition, personal hygiene, and family planning counseling and method provision.

\footnotetext{
${ }^{1}$ The protocol used in this OR study was an adaptation of the home visits protocol developed by the Communication for Healthy Living Project (CHL), which included a total of six home visits distributed as follows: day 2 by the nurse alone, day 4 and 7 by the nurse and RR together and days 14, 21 and 35 by the RR alone.
} 
- Quarterly home visits by the RR to women in the extended postpartum period (12 months after delivery) to educate the mother about infant nutrition and health; to support the mother's use of contraception and to answer any questions related to family planning.

\section{IEC materials}

Existing IEC materials were used to enhance messages on birth spacing and postpartum use of contraception. These included a birth spacing poster, a flipchart for $R R s$ to use during home visits, a flier on breastfeeding, and a flier on postpartum use of contraception after the first child. ${ }^{2}$ Two additional IEC materials were developed specifically for this project, namely a wall chart showing services to be offered to the mother and newborn at the day 40 postpartum visit, and a birth spacing flier encouraging 3-5 year birth spacing, providing criteria for effective use of LAM and listing postpartum methods of contraception. The flier was developed in collaboration with the CHL Project to target low parity women and their husbands.

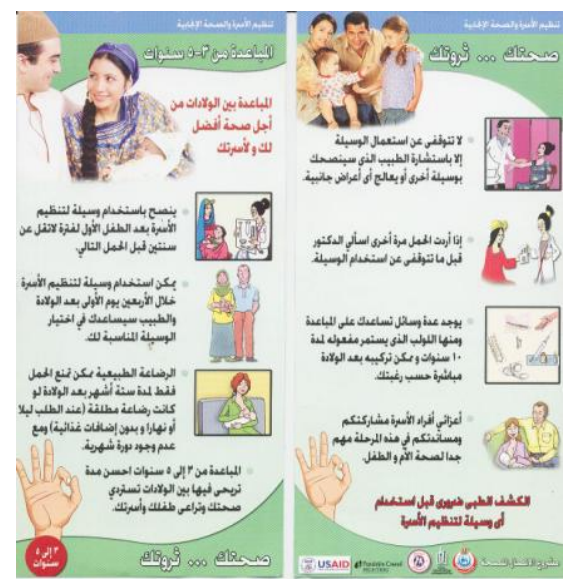

\section{Awareness raising activities for men}

Community leaders in intervention villages conducted seminars, one-on-one meetings, and informal gatherings for husbands to enhance their knowledge of birth spacing and to solicit their support for postpartum use of contraception. Additionally, MOHP communication officers organized monthly seminars for men where different $\mathrm{MCH}$ issues, including birth spacing, were discussed. The unit doctor and local religious leaders (Moslem and Christian) were also expected to attend those meetings, where relevant brochures and fliers were to be handed out to participants.

\section{Implementation of the intervention}

The above intervention was implemented in a total of 20 clinics in Assiut and Sohag governorates over a six month period (December 2005 - May 2006).

Each clinic received an updated copy of MOHP service guidelines for antenatal and postpartum care services. This set of guidelines included a section on birth spacing and effective use of LAM in the antenatal care protocol and also included a recommendation for joint home visits in the postpartum care protocol. Each clinic also received a copy of the updated service delivery guidelines on management of contraceptive side effects, developed by TAHSEEN/CATALYST Project and MOHP.

Health care providers in the study clinics received training on the above integrated service delivery protocols. A step-down training approach was used for training providers and supervisors. First, FP and MCH managers and supervisors from the Health Directorates received a three day training of trainers (TOT) course, held in Cairo. The TOT was followed by a three

\footnotetext{
${ }^{2}$ These IEC materials were developed by the SIS/IEC Center and MOHP with technical assistance from the CHL project.
} 
day training course for health care providers (physicians, nurses, and $R R s$ ) and district level supervisors held in the respective governorate capital city.

The last training component included a two day orientation workshop for community leaders in villages where Model II was implemented, i.e. where community awareness activities for men were to be undertaken. Community influentials included religious leaders, school teachers, village Omdas (chiefs), agriculture extension workers (AEWs), and clinic auxiliary staff who are known to play an active role in their communities. Workshop participants were introduced to concepts of birth spacing and male responsibility for the health of their wives and children, and learned about postpartum FP methods and the importance of antenatal and postpartum visits and communication skills.

In total, 18 governorate-level supervisors received TOT and subsequently over 200 health providers and 50 community influentials were then trained. Table 2 shows total number of participants trained.

Table 2: Different types of training that were offered in the study

\begin{tabular}{|l|l|}
\hline \multicolumn{1}{|c|}{ Participants } & \multicolumn{1}{c|}{ Type of training } \\
\hline Governorate managers / supervisors $(\mathrm{n}=18)$ & Training of trainers (TOT) \\
\hline District managers / supervisors $(\mathrm{n}=28)$ & Step-down training \\
\hline Physicians, MCH nurses, FP nurses, RRs $(\mathrm{n}=180)$ & Step-down training \\
\hline Community leaders $(\mathrm{n}=50)$ & Orientation workshop \\
\hline
\end{tabular}

IEC materials were distributed by the IEC officers to the 20 intervention clinics in each of the study governorates; each intervention clinic received a copy of the birth spacing poster and the Day 40 Visit poster. Clinic staff were advised to place the Birth Spacing poster in the antenatal care exam room and the Day 40 Visit poster in the waiting area, to increase awareness among visiting pregnant and postpartum women. In addition, each clinic received hundreds of copies of fliers, addressing topics such as breastfeeding, birth spacing and postpartum use of contraception. Nurses were instructed to hand out fliers to pregnant and postpartum women during antenatal care and day

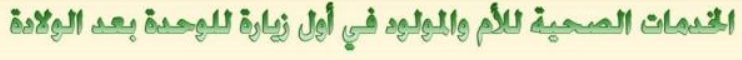
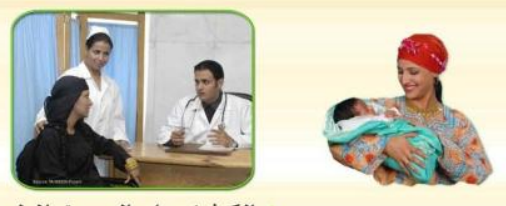
ه الكشف على السيدة والمولود

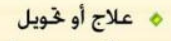

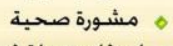
ه إعطاء وسيلة لتنظيم الأسرة
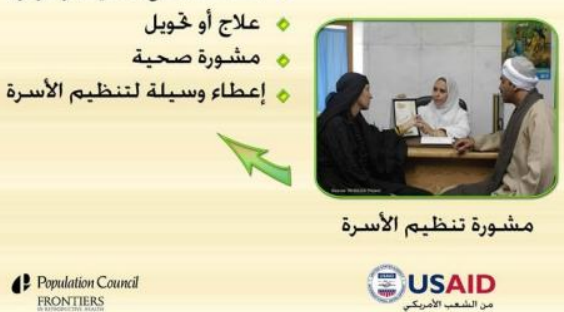

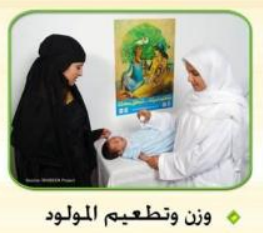

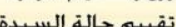
o تثقيف صحي حال الثي

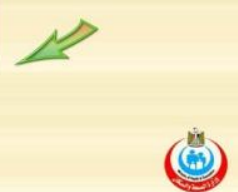
40 postpartum visits. It was noted during field visits that some nurses were not distributing fliers to women for fear of running out of stock. Upon discovering this, nurses were reassured that they would receive additional materials upon request, if needed.

Seminars for men were organized by the district and the governorate IEC officers. A total of 5-6 seminars were held in each intervention village over the duration of the intervention. On average, 30-40 participants attended each seminar, which was 1-1.5 hours long. It was noted that men's 
turnout was low, especially among the target group of young married men with 0-1 living children. To improve men's attendance rates, IEC officers were instructed to hold the seminars in the evening and to advertise them well in advance. Additionally, each final community seminar included a contest where participants were asked a set of five questions related to program content and those who answered correctly received nominal prizes.

These activities were undertaken over a five-month period. Clinic staff and IEC officers received monthly supervision and monitoring visits by governorate and district $\mathrm{MCH}$ and FP supervisors, who were encouraged to make joint supervisory visits. A special checklist was developed for monitoring each component of the intervention, a copy of which is in appendix A. In addition, FRONTIERS Program staff and MOHP central office staff made periodic visits to these clinics and held monthly meetings with the governorate and district teams to discuss issues related to implementation and possible resolutions. For example, the number of postpartum home visits was reduced to five, after RR and MCH nurse supervisors complained of the difficulty in making all required visits. Rapid turn-over among physicians was another issue, and this was resolved with on-the-job training and a one day refresher course for new physicians. The Undersecretaries for FP and MCH in Cairo were updated regularly on the progress of the project through steering committee meetings held every two months.

\section{Sources of Data}

1. Structured interviews were held with 36 physicians, 26 FP nurses, $89 \mathrm{MCH}$ nurses and $39 R R \mathrm{~s}$ from the 20 intervention Health Units to solicit their views on the program's implementation and feasibility of scale up.

2. Exit interviews were undertaken with pregnant women (6-9 months) who had 0-1 living children and who were seeking antenatal care in the three sets of clinics to assess the intervention's effect on their knowledge and attitudes. In order to detect a difference in contraceptive use at 12 months between the three study groups, a sample size of 550 women would be needed for each study group, i.e. 55 pregnant women per clinic. This sample size was based on the following assumptions: i) baseline contraceptive use in the extended postpartum period in the control group was estimated at 10 percent; the minimal increase in use to be considered statistically significant was $5 \%$; alpha $=0.05$; power $=0.8$; a design effect of 1.5 (i.e. moderate intra-cluster correlation); and a $10 \%$ loss to follow up. Even after extending the data collection period by an additional month, the total number of women recruited was 1,416 (see Table 3 ). No refusals were reported among women who were approached for the exit interview.

\section{Table 3: Number of recruited women at each phase of data collection}

\begin{tabular}{|l|c|c|c|}
\hline & Target sample & N recruited & \% achievement \\
\hline ANC exit interview & 1,650 & 1,416 & 86.0 \\
\hline 4 month postpartum home interview & 1,416 & 1,409 & 99.5 \\
\hline $10-12$ month postpartum home interview & 1,413 & 1,409 & 99.7 \\
\hline
\end{tabular}

3. Home interviews were then conducted with the same group of women at 4 months and 10-12 months postpartum to assess the impact of the intervention on their contraceptive behavior 
and birth spacing intentions (see Table 3). All except seven women were traced and completed the 4 month interview; four mothers who were traveling at four months were contacted for the 10-12 month interview. It should be noted, however, that due to the need to complete data collection by September 2007, the second home interview was conducted earlier than 10 months for about one quarter of women as shown in Table 4.

\section{Table 4: Percent distribution of women by time of second home interview}

\begin{tabular}{|l|c|}
\hline \multicolumn{1}{|c|}{ Month of interview } & \% of women \\
\hline$<10$ months & $22.4(\mathrm{n}=312)$ \\
\hline $10<11$ months & $38.4(\mathrm{n}=536)$ \\
\hline $11-12$ months & $39.2(\mathrm{n}=547)$ \\
\hline Total & 1,395 \\
\hline
\end{tabular}

4. In-depth interviews were held with 12 local MOHP managers and supervisors at the two study governorates (Directors of Family Planning and of Maternal and Child Health, Nurse Supervisors, RR supervisor) to solicit their views on implementation of the intervention, its acceptability and the feasibility of scaling up. Table 5 shows distribution of governorate and district supervisors have completed in-depth interview.

\section{Table 5: Distribution of managers and supervisors who participated in in-depth interviews}

\begin{tabular}{|l|c|}
\hline Position & $\mathbf{n}$ \\
\hline Director of FP (governorate level) & 2 \\
\hline Director of MCH (governorate level) & 2 \\
\hline MCH nurse supervisor (governorate / district) & 2 \\
\hline FP nurse supervisor (district level) & 2 \\
\hline$R R$ supervisor (governorate / district) & 2 \\
\hline Health district manager & 2 \\
\hline Total & $\mathbf{1 2}$ \\
\hline
\end{tabular}

5. Focus group discussions were held with trained community influentials in communities that implemented community awareness activities for men. These FGDs solicited community influentials' views on implementation of the awareness raising activities and on husbands' general reactions to birth spacing messages. A total of 30 trained community leaders attended the above FGDs (an average of 7-8 participants per FGD).

6. Focus group discussions were held with husbands of low parity women in the three study groups, comparing their knowledge and attitudes about birth spacing and postpartum use of contraception. FGDs were facilitated by SPAAC interviewers with logistic support provided by IEC officers and $R R s$.

7. Service statistics data from each Health Unit (total of $30 \mathrm{HUs)}$ on utilization of $\mathrm{MCH}$ and FP services, during the three months prior to the intervention (October - December 2005) and one year after the intervention (March - May 2007). 


\section{STUDY RESULTS}

\section{Participants' Characteristics}

\section{Pregnant women}

Table 6 describes then characteristics of women who completed the exit interview. Women in the three study groups were comparable on age, number of living children and previous use of contraception. However, women who received the health services model reported having higher levels of schooling and were married for fewer years compared to the other two groups $(p<0.01)$. Women in the community awareness model were less likely to be working for cash compared to the other two groups $(\mathrm{p}<0.01)$.

\section{Health providers}

On average, each study clinic had 1.8 doctors, 1.3 FP nurses, $2 R R$ s and 4.4

$\mathrm{MCH}$ nurses. It is notewo
Table 6: Demographic characteristics of pregnant women who were enrolled in the study (by study group)

\begin{tabular}{|c|c|c|c|}
\hline & $\begin{array}{c}\text { Health } \\
\text { Services } \\
\text { Model }\end{array}$ & $\begin{array}{c}\text { Community } \\
\text { Awareness } \\
\text { Model }\end{array}$ & Control \\
\hline Age $\quad \mathrm{N}$ & 550 & 481 & 385 \\
\hline $\begin{array}{l}\text { Mean age in years } \\
\text { St. Dev. }\end{array}$ & $\begin{array}{l}22.6 \\
(3.56)\end{array}$ & $\begin{array}{c}22.1 \\
(3.36)\end{array}$ & $\begin{array}{l}22.0 \\
(3.71)\end{array}$ \\
\hline 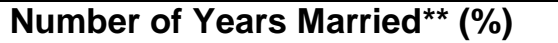 & & & \\
\hline $\begin{array}{l}\text { Less than one year } \\
1-2 \text { years } \\
3-5 \text { years } \\
6-9 \text { years } \\
\text { Mean (years) }\end{array}$ & $\begin{array}{c}26.5 \\
33.8 \\
31.3 \\
8.4 \\
2.2 \\
\end{array}$ & $\begin{array}{c}22.3 \\
29.5 \\
36.0 \\
12.1 \\
2.6 \\
\end{array}$ & $\begin{array}{c}19.2 \\
33.2 \\
37.7 \\
9.9 \\
2.5 \\
\end{array}$ \\
\hline Level of Education ${ }^{\star \star}$ & & & \\
\hline Did not enter school & 39.3 & 49.1 & 49.6 \\
\hline $\begin{array}{l}\text { Completed primary or } \\
\text { preparatory }\end{array}$ & 16.7 & 15.6 & 20.8 \\
\hline $\begin{array}{l}\text { Completed secondary or } \\
\text { vocational }\end{array}$ & 36.0 & 29.7 & 25.4 \\
\hline Completed university degree & 8.0 & 5.6 & 4.2 \\
\hline $\begin{array}{l}\text { Work for Income Status }{ }^{\star \star} \\
\% \text { Work }\end{array}$ & 9.8 & 3.7 & 7.3 \\
\hline Number of Children (\%) & & & \\
\hline No children & 61.8 & 57.4 & 57.1 \\
\hline One girl & 17.5 & 21.8 & 21.8 \\
\hline One boy & 20.2 & 20.6 & 21.0 \\
\hline Twins & 0.6 & 0.2 & \\
\hline $\begin{array}{l}\text { Experience with Contraceptives } \\
\% \text { previously used contraceptives }\end{array}$ & 14.0 & 15.2 & 14.0 \\
\hline
\end{tabular}

$$
{ }^{* *} p<0.01
$$

themselves as "Takamol nurses", meaning that they had been trained by the USAID-funded Takamol project to have combined duties of FP and MCH nurses.

As shown in Table 7, most physicians and $R R s$ in the study clinics reported working at that clinic for one year or less (67 percent of physicians and 72 percent of $R R \mathrm{~s}$ ), which suggests a rapid turnover among healthcare staff within these two occupational groups. $\mathrm{MCH}$ and FP nurses were somewhat more likely to be stable in their clinics, with half of FP nurses reporting to work for 10 or more years in their respective clinics. 
Table 7: Percent distribution of providers by occupation and duration of work at study clinic

\begin{tabular}{|l|c|c|c|c|}
\hline Duration at study clinic & Physicians & FP Nurses & MCH Nurses & $\boldsymbol{R R s}$ \\
\hline $\mathbf{N}$ & $\mathbf{3 6}$ & $\mathbf{2 6}$ & $\mathbf{8 9}$ & $\mathbf{3 9}$ \\
One year or less & 66.7 & 11.5 & 13.5 & 72.4 \\
2 to 4 years & 22.2 & 11.1 & 24.7 & 5.1 \\
5 to 9 years & 5.6 & 23 & 39.3 & 7.7 \\
10 or more years & 5.6 & 50 & 22.5 & 15.4 \\
\hline
\end{tabular}

\section{Health supervisors}

Nine of the 12 directors/supervisors had been in their current position for 5-10 years. The two health district directors interviewed had been in office for less than two years. The $R R$ supervisor in one of the health districts had been a rural Raida for ten years and was promoted to a Supervisor six months before the interview.

\section{Community influentials}

Trained community influentials who participated in the FGDs were most likely to be religious leaders or technicians affiliated with the health unit (i.e. sanitarian, health clerk, or nutritionist). They were also likely to have completed secondary or technical education, and two had completed university education. Both groups of community influencers had a large number of children (average $=4$ ); other characteristics of trained influentials are shown in Table B1 in Appendix B.

\section{Husbands}

The husbands who participated in the FGDs $(\mathrm{n}=12)$ were mostly in their late 20 s to early 30s. More husbands in the control group had completed secondary education compared to husbands in both intervention groups, and more Model II husbands worked as farmers compared to those in the Model I and control groups. Characteristics of husbands who participated in FGDs are presented in Table B2 in Appendix B.

\section{Exposure to the Intervention}

This section presents results pertaining to exposure of low parity women and husbands to different components of the intervention. Data presented in this section are based on results of interviews with women and FGDs with husbands.

\section{Services for low parity women}

Table 8 presents data on the health services and messages received by women during antenatal and postpartum care. Women in both intervention groups were significantly more likely to be counseled on birth spacing, to be advised to wait 3-5 years before the next pregnancy, to be told about suitable postpartum contraceptive and to receive relevant brochures/fliers during their antenatal care visit. 
Very few women in both sets of clinics mentioned being advised during antenatal care on a suitable contraceptive method to use while breastfeeding, or about the three conditions that should be met for effective use of LAM.

Table 8: Low parity women's reports on services received at prenatal care, postpartum and extended postpartum period

\begin{tabular}{|c|c|c|c|}
\hline & $\begin{array}{c}\text { Health } \\
\text { services } \\
\text { model }\end{array}$ & $\begin{array}{c}\text { Community } \\
\text { awareness } \\
\text { model }\end{array}$ & Control \\
\hline $\begin{array}{l}\text { Prenatal care visit } \\
\text { Completed exit interview (N) } \\
\text { Counseled on birth spacing }{ }^{\star * \star} \\
\text { Advised to wait } 3-5 \text { years for next child }{ }^{\star * *} \\
\text { Explained importance of spacing } \\
\text { Told conditions of BF to avoid pregnancy* } \\
\text { Advised to use FP by } 40 \text { th day PP** } \\
\text { Advised on suitable contraceptives while BF } \\
\text { Three conditions for LAM }{ }^{\star * *} \\
\text { Told suitable PP contraceptives }{ }^{\star * *} \\
\text { Given brochures }\end{array}$ & $\begin{array}{c}550 \\
\% \\
63.3 \\
58.2 \\
44.7 \\
18.4 \\
50.9 \\
7.8 \\
18.4 \\
61.8 \\
53.3 \\
\end{array}$ & $\begin{array}{c}481 \\
\% \\
41.6 \\
40.5 \\
18.7 \\
11.4 \\
23.9 \\
5.8 \\
11.4 \\
47.0 \\
41.1 \\
\end{array}$ & $\begin{array}{c}385 \\
\% \\
8.3 \\
5.2 \\
3.6 \\
1.3 \\
5.2 \\
1.0 \\
1.4 \\
12.2 \\
7.5 \\
\end{array}$ \\
\hline 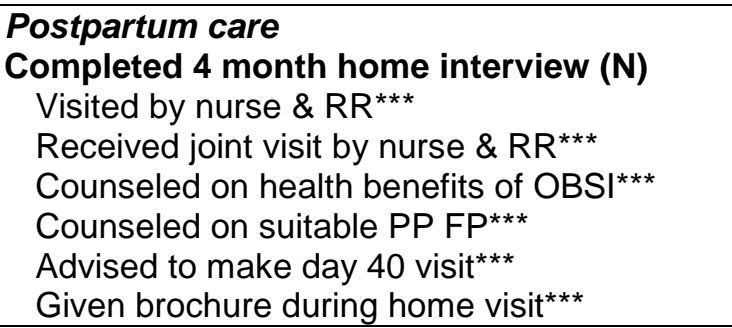 & $\begin{array}{l}\mathbf{5 4 8} \\
76.5 \\
67.2 \\
29.0 \\
36.0 \\
37.0 \\
59.9\end{array}$ & $\begin{array}{l}476 \\
69.7 \\
58.8 \\
46.8 \\
51.9 \\
49.3 \\
60.9\end{array}$ & $\begin{array}{l}385 \\
3.9 \\
2.3 \\
2.1 \\
4.7 \\
4.2 \\
4.4 \\
\end{array}$ \\
\hline 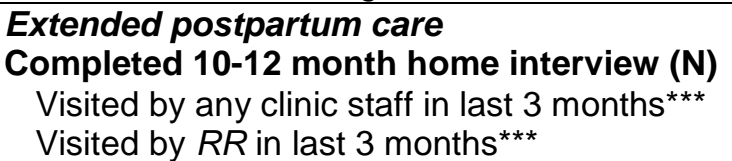 & $\begin{array}{l}\mathbf{5 4 6} \\
57.5 \\
38.3\end{array}$ & $\begin{array}{l}479 \\
77.0 \\
58.0\end{array}$ & $\begin{array}{l}384 \\
7.0 \\
4.7\end{array}$ \\
\hline
\end{tabular}

${ }^{*} p<0.05 \quad{ }^{* *} p<0.01 \quad{ }^{* * *} p<0.001$

It is noteworthy that Model I clinics offered more components of birth spacing counseling compared to Model II clinics, namely advising women to practice birth spacing, advising women to postpone next pregnancy for 3-5 years, explaining importance of birth spacing to pregnant women and discussing postpartum contraception. There are a number of possibilities for this discrepancy, including that supervision in the two Model II districts was less rigorous than the Model I districts and that a change of leadership took place in one of Model II's districts a few months after the project was initiated.

The majority of women interviewed in the two intervention communities were visited by an $R R$ and a nurse for postpartum visits and most of them received a joint visit by the two together, as intended. Yet the content of the visits differed according to group; a larger proportion of women in the Model II group reported being counseled on the health benefits of birth spacing, postpartum family planning methods, and were advised to go to the health unit on the $40^{\text {th }}$ day postpartum. However, approximately equal proportions of women in both intervention groups reported receiving brochure(s) during home visits, when compared to the control group. 
At 10-12 months postpartum, women were asked if they had been visited by any clinic staff member during the preceding three months, and if "yes", by whom. As shown in Table 8, much more women in both intervention groups were visited by someone from the clinic. Moreover, an $R R$ was more likely to visit women in model I or model II communities than control communities during the three months preceding the home interview.

These findings indicate that the prenatal care services were better implemented in Model I than in Model II clinics, while the home visits were better implemented in Model II than Model I clinics. This difference could be because the two $R R$ supervisors in the Model II districts were more motivated and provided better supervision than the $R R$ supervisors in Model I districts. It is worth noting that a few women in control group facilities did receive some of the integrated birth spacing services, perhaps as a result of communication among supervisors across different health districts.

\section{Community awareness activities for husbands}

Several of the husbands interviewed in Model II communities ( 7 out 15 in Assiut and 9 out of 17 in Sohag) said they had been exposed to birth spacing messages through community seminars or from a community leader while sitting in a coffee shop and / or from health facility staff. Five more husbands mentioned that they did not attend the intervention seminars themselves, but they knew people who did.

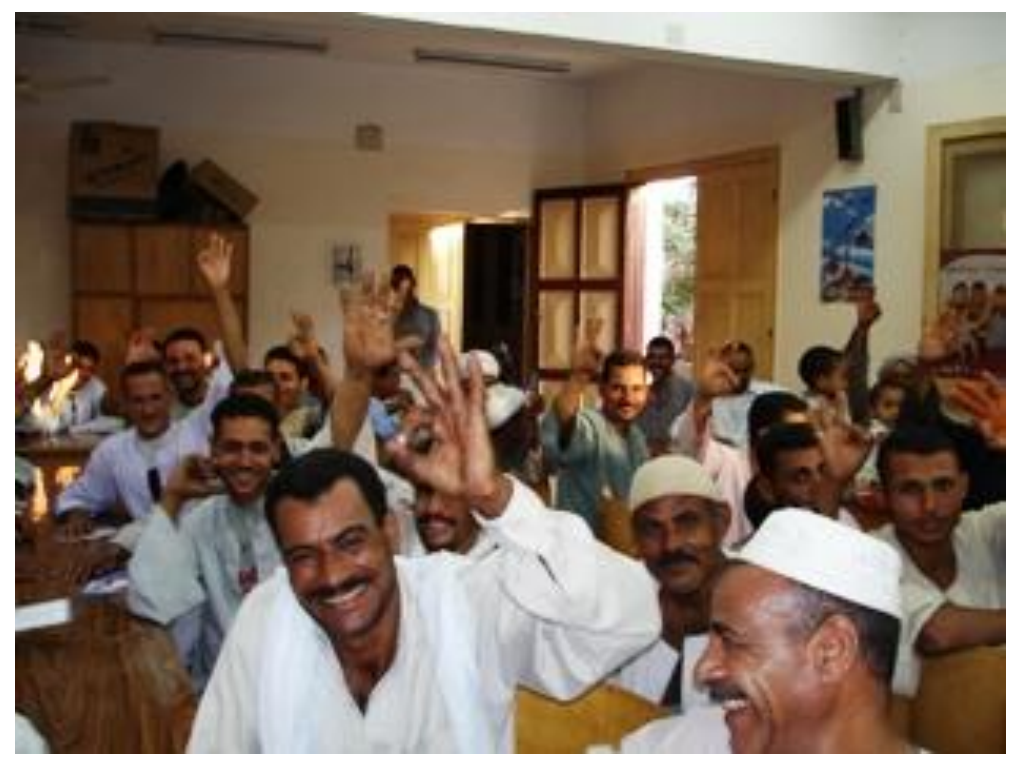

"I heard about those seminars and actually attended one where a Sheikh and a communication officer talked about breastfeeding, birth control methods and planning ...” (Male FGD participant from Assiut)

"I attended one or two seminars where they discussed that stuff...They were organized by Mr. Mahmoud, the Agriculture Extension Worker...There was also one at the health unit and one at the Mosque ..." (Male FGD participant from Sohag). 


\section{Acceptability of the Intervention}

\section{Women's views}

Upon exit from the clinic, low parity women were asked if they would agree to the doctor or nurse speaking to them about birth spacing during an antenatal care visit. Table 9, shows that virtually all low parity women in all three groups did not mind receiving advice on birth spacing during antenatal care. Interestingly, more women in Model II communities and in control communities said they would only accept a physician talking to them.

Women's views regarding the quality of services received during antenatal and postpartum care were used in this study as a proxy for the acceptability of the intervention's different components. At each phase of data collection, women were asked to rate the quality of services they received as "good", "reasonable" or "bad". Additionally, in the 10-12 month home interview women were asked to rate the overall quality of

Table 10: Low parity women's views on quality of prenatal and postpartum care services received (by study group)

\begin{tabular}{|l|c|c|c|}
\hline & $\begin{array}{c}\text { Health } \\
\text { services } \\
\text { model }\end{array}$ & $\begin{array}{c}\text { Community } \\
\text { awareness } \\
\text { model }\end{array}$ & Control \\
\hline Prenatal care services & 550 & 481 & 385 \\
N completed exit interview & 98.0 & 95.0 & 80.5 \\
\% Described services as good*** & & & \\
\hline Postpartum home visits & 419 & 366 & 57 \\
N received postpartum home visits & 91.5 & 93.4 & 87.7 \\
\% Found home visits useful & 342 & & \\
\hline Day 40 visit to clinic & 92.1 & 326 & 127 \\
N made day 40 visit to clinic & & & \\
\% described services as good & & & \\
\hline Quarterly home visits & 314 & 369 & 27 \\
N received home visit within last 3 & 95.2 & 100.0 & 100.0 \\
months & & & \\
\% found visit useful & & & \\
\hline $\begin{array}{l}\text { Overall assessment of prenatal and } \\
\text { postpartum care services }\end{array}$ & 546 & 479 & 384 \\
N completed 10-12 month home & 79.5 & 71.8 & 56.0 \\
interview & & \\
\% described services as good & & & \\
\hline
\end{tabular}

${ }^{* *} p<0.01 \quad{ }^{* * *} p<0.001$
Table 9: Percent distribution of low parity women by acceptance of birth spacing discussions during antenatal care

\begin{tabular}{|l|c|c|c|}
\hline & $\begin{array}{c}\text { Health } \\
\text { Services } \\
\text { model }\end{array}$ & $\begin{array}{c}\text { Community } \\
\text { awareness } \\
\text { model }\end{array}$ & Control \\
\hline & & & \\
\hline $\mathbf{N}$ & $\mathbf{5 5 0}$ & $\mathbf{4 8 1}$ & $\mathbf{3 8 5}$ \\
Do not accept & 5.3 & 2.5 & 6.2 \\
Accept if by physician & 19.1 & 31.2 & 29.3 \\
Accept if by nurse & 8.0 & 11.4 & 15.3 \\
Accept by either & 67.6 & 54.9 & 49.1 \\
\hline
\end{tabular}

Source: Exit interview with pregnant women antenatal and postpartum care they received over the last 12 months.

Table 10 shows that a significantly larger proportion of women in the two interventions groups, compared to the control group, described the antenatal care received as good and described the 40 day postpartum clinic visit as good. There were no statistically significant differences among women in the three groups with regards to views on usefulness of the early postpartum home visits by nurse or $R R$ ). 
Interestingly, fewer women who received the quarterly home visit in Model I communities were satisfied with the visit when compared to women in Model II or control communities. This may reflect higher expectations among women who had attended Model I clinics and reported being more satisfied with their antenatal services and/or because they also had higher levels of schooling. At 10-12 months postpartum, about three quarters of women in both intervention groups described services as good and nothing requiring improvement, compared to only half of women in the control group.

\section{Husbands' views}

Husbands who attended birth spacing seminars spoke positively of their experience and described them as useful. One suggestion made from this group was to hold the seminars more frequently.

"Those seminars should be held at close intervals .. let's say every six months or even every two months so people won't forget what was said ..."(Male FGD participant from Sohag)

When asked about ways to convince husbands to support birth spacing, husbands in Model II communities suggested raising men's awareness by informing them of the health risks of closely-spaced pregnancies on mother and child and providing educational messages through religious sermons, TV, health facility staff and/or seminars led by community leaders. Seminar participants stressed the importance of involving the religious leaders in the seminars, who then use verses from the Quran or Prophet's sayings to inform people of the messages. However, one participant stressed that seminar speakers should present themselves as role models to men, saying that a religious leader with seven children would not be the right person to promote birth spacing to others.

"When I get the advice from a health specialist I will be convinced, but if it said without mentioning reasons it won't be convincing” (One FGD participant from Assiut)

"Choosing speakers who can convince people is important...They should have a style and a special way of talking to people ..." (One FGD participant from Sohag)

\section{Health providers' views}

Health care providers in all 20 intervention clinics were asked about the extent that it would be possible to implement different components of the intervention and whether it would be feasible to expand the intervention to the national level. As shown in Table 11, the majority of health providers interviewed said that they had heard of the "MCH and FP integration" Project. A larger proportion of FP nurses and $R R s$ in both governorates reported receiving offsite training on birth spacing, compared to doctors and $\mathrm{MCH}$ nurses. This low recall among doctors was probably a result of a large turnover among physicians and because a maximum of four nurses per clinic (only those who provide antenatal or postpartum care) were trained. 
Table 11 : Service providers' exposure to the intervention (by occupation)

\begin{tabular}{|l|c|c|c|c|}
\hline & Physicians & $\begin{array}{c}\text { FP } \\
\text { nurses }\end{array}$ & $\begin{array}{c}\text { MCH } \\
\text { nurses }\end{array}$ & $\boldsymbol{R R}$ \\
\hline $\mathrm{N}$ & 36 & 26 & 89 & 39 \\
\hline $\begin{array}{l}\text { \% Providers who Heard of MCH \& FP } \\
\text { \%tegration Project }\end{array}$ & 97.2 & 100 & 96.62 & 100 \\
training & 66.7 & 88.5 & 51.7 & 97.4 \\
\hline
\end{tabular}

Table 12 shows that some components of the birth spacing counseling that should have been discussed during prenatal care and postpartum care services was not mentioned by the service providers. Counseling topics most likely to be mentioned by providers were birth spacing for 3-5 years and counseling on appropriate postpartum contraceptive methods. Topics that were less likely to be mentioned included counseling on FP use by $40^{\text {th }}$ day postpartum, counseling on conditions for successful use of LAM and encouraging the mother to make the $40^{\text {th }}$ day postpartum visit. When asked why these topics were not frequently discussed during counseling, the main reasons were "mother's condition did not allow" and "provider not confident women would accept advice".

Table 12: Service providers' reports on counseling topics provided during antenatal care (by occupational group)

\begin{tabular}{|l|c|c|c|c|}
\hline $\begin{array}{l}\text { Topics on which clients were counseled during } \\
\text { prenatal care (\%) }\end{array}$ & Physicians & $\begin{array}{c}\text { FP } \\
\text { nurses }\end{array}$ & $\begin{array}{c}\text { MCH } \\
\text { nurses }\end{array}$ & RRs \\
\hline $\mathbf{N}$ & 35 & 26 & 86 & 39 \\
Counseling on suitable postpartum contraceptive & 77.2 & 51.2 & 83.7 & 82.05 \\
Counseling on contraceptive use on $40^{\text {th }}$ day postpartum & 62.9 & 50 & 51.2 & 69.23 \\
Counseling on conditions for LAM & 71.43 & 69.2 & 59.3 & 66.7 \\
Encouraged mother to make $40^{\text {th }}$ day visit & 48.5 & 50 & 52.3 & 56.4 \\
\hline
\end{tabular}

Table 13 describes the two services that were mentioned by providers as being most likely to be provided. Encouraging women to start contraception by the $40^{\text {th }}$ day postpartum and supporting postpartum home visits were the most provided services, and the services least likely to be implemented were encouraging women to make the $40^{\text {th }}$ day postpartum visit and providing an integrated service to mother and child on the $40^{\text {th }}$ day visit.

All RRs and the majority of $\mathrm{MCH}$ nurses reported making postpartum home visits. Interestingly, more than half of the family planning nurses reported making home visits, even though MOHP service delivery protocols did not require them to make do so in the early postpartum period.

All providers, with the exception of one MCH nurse in Assiut and one physician in Sohag, believed that the activities promoted under this project could be sustained. Moreover, a majority of health service providers believed that the activities should be implemented at a national scale. Several suggestions were made by providers to the MOHP central level, the Health Directorate and Health District, to improve program sustainability, and a full listing of these provider suggestions is provided in Table B3 in Appendix B. 
Table 13: Service providers' reports on services provided during postpartum period (by occupational group)

\begin{tabular}{|l|c|c|c|c|}
\hline Services provided during postpartum period (\%) & Phys. & $\begin{array}{c}\text { FP } \\
\text { Nurses }\end{array}$ & $\begin{array}{c}\text { MCH } \\
\text { nurses }\end{array}$ & $\boldsymbol{R}$ \\
\hline N & 35 & 26 & 86 & 39 \\
Counseling on LAM Conditions & 82.9 & 61.5 & 61.6 & 84.6 \\
Encourage Contraception by 40 & th \\
Supporting PP home visits $_{\text {Encourage 40 }}^{\text {th }}$ PP day health unit visit & 80 & 84.6 & 91.9 & 76.9 \\
Provide integrated services to mother and child on 40th day visit & 74.3 & 84.6 & 91.9 & 84.6 \\
Counsel on or select suitable contraceptive on 40 ${ }^{\text {th }}$ day visit & 77.3 & 53.8 & 52.3 & 64.1 \\
Conduct home visits & 42.1 & 65.4 & 59.3 & 61.5 \\
\hline
\end{tabular}

The most popular suggestions for the central level from health service providers were to give more monetary incentives to health providers and to provide continuous training. The Directorate level providers' requests included an increase in friendly and supportive supervision and increasing continuous training of health providers. Improved supervision was an additional need mentioned at the Health District level. At the level of the health facility, the majority of providers mentioned that they need to work better as a coordinated team.

Table 14: Percentage distribution of health providers by views on sustainability of the intervention

\begin{tabular}{|l|c|c|c|c|}
\hline Service providers' views & Phys. & $\begin{array}{c}\text { FP } \\
\text { Nurses }\end{array}$ & $\begin{array}{c}\text { MCH } \\
\text { nurses }\end{array}$ & Raidat \\
\hline $\mathbf{N}$ & $\mathbf{3 5}$ & $\mathbf{2 6}$ & $\mathbf{8 6}$ & $\mathbf{3 9}$ \\
$\begin{array}{l}\text { Believed intervention could be sustained } \\
\text { in study clinics }\end{array}$ & 97.1 & 100 & 98.8 & 100 \\
$\begin{array}{l}\text { Believed all health units should implement } \\
\text { integrated MCH \& FP Services }\end{array}$ & 88.6 & 100 & 95.3 & 94.9 \\
\hline
\end{tabular}

\section{Supervisors' views}

Managers and supervisors were favorable of supporting the intervention and its scale up. They felt the intervention improved the quality as well as utilization of services, and also viewed integration of $\mathrm{MCH}$ and family planning services as useful and essential. However, one official argued that birth spacing was not the right concept to promote in view of the national population target of reducing fertility and achieving a replacement level fertility by the year 2017. This official believed that the health team should emphasize both birth spacing and limiting, depending upon the woman's reproductive situation.

"The spacing message is not good for all women ..." (Health supervisor in Assiut governorate). 
Health officials supported birth-spacing counseling for pregnant women in the Assiut governorate, but officials in Sohag were not as supportive, as some husbands and mothers-in-law misinterpreted the intervention as a government effort to stop women from having children. Officials stated that some women may require a longer period of time to fully understand the messages and follow birth spacing recommendations, and hence they supported the incorporation of community influentials to assist in the promotional efforts of the intervention.

Upon probing about specific program activities that warranted scaling up, the officials felt that birth spacing counseling and offering postpartum contraception during prenatal care had significantly helped improve the quality of prenatal care services and should be scaled up within all of Egypt's health facilities. These officials also felt that this scale-up should be supported by the Ministry (central office) and Health Directorates in efforts to reduce maternal and infant mortality and improve the health of mothers and children.

"Quality of antenatal care services has improved; antenatal care coverage increased as well as utilization of services because people felt that they were receiving a service and health education that they benefited from..." (District manager in Assiut governorate)

Health officials positively regarded the postpartum home visits and believed that they offered an opportunity for integrating health care and health education messages to women. Requiring the $R R$ to make two of the visits evidently reduced the workload for the $\mathrm{MCH}$ nurse. This system also benefited from the $R R$ 's communication expertise and her close relationships with the women she served. These postpartum home visits were considered essential, scale-up was encouraged and officials felt that these visits should be enforced with continuous follow-up from District and Directorate Supervisors, monthly supervisory meetings, and providing transportation facilities.

Contrarily, four officials complained about the large number of home visits, which they considered to be unacceptable to some women and posed a burden on the MCH nurse.

"The large number of home visits was boring for some women ... I think the most important visit for the Raeda is the one on day 35 for family planning while for the MCH nurse, I think the first two are important and the third could be dropped ... "(FP manager)

All health officials agreed that the comprehensive services provided during the $40^{\text {th }}$ day postpartum visit were useful and feasible. Officials believed them to be acceptable to both health providers and women, and utilization of day 40 services increased in response to the intervention. Four officials demonstrated concern about the quality of the services as clinic demand increased, but health service providers are making efforts to ensure clinic capacity.

"In Tema and Tahta we do not have a problem because we have plenty of nurses but there might be a problem in the southern districts because they do not have enough nurses ..." (Nurse supervisor in Sohag)

Health officials appreciated the protocols and IEC materials developed; they were considered clear, organized and high quality and greatly assisted in the service delivery. Unfortunately, it was noted that some health providers did not distribute their fliers and IEC materials to the extent 
expected, for fear of not receiving additional copies or believing the materials were personal property and not for sharing among colleagues.

All health officials agreed that integrated supervision was useful because it ensured better quality of services. Some of the problems and constraints mentioned regarding integrated supervision were the limited transportation facilities and the lack of coordination among MCH and FP staff.

\section{Community influentials views}

All influentials mentioned that they communicated information on birth spacing to men in their communities to his/her own capacity and mentioned participating in community seminars to raise husbands' awareness of birth spacing. Religious leaders talked to men at the mosque while others talked to men in coffee shops, public cars, at work, and among individual friend and family networks.

"I would speak with every husband who came to the health bureau to register his newborn ... I would tell him he should space and plan ..." (A health clerk in Sohag governorate)

"At religious sermons at the mosque I used to answer questions related to that topic to show the religious point of view... I also organized a seminar at my house ..." (A religious leader in Assiut governorate)

As to specific messages on birth spacing, influentials concentrated on the health of the first child, the health of the mother, and the strain on parents from having more children. Interestingly, none of the influentials in either governorate mentioned the negative health effects of closely spaced pregnancies on the subsequent pregnancy (i.e. maternal and fetal complications, such as low birth weight).

Husbands were thought to be generally supportive of birth spacing. In Assiut, men responded well to the benefits of birth spacing that were mentioned, yet community leaders reported difficulties when attempting to convince illiterate men of the benefits of birth spacing; this population was more receptive to messages associated with health risks to the mother and child. In Sohag, influentials mentioned that husbands accepted spacing mostly for financial reasons. One religious leader added that some husbands continued to be undecided because they did not know if birth spacing was considered halal (religiously acceptable).

Community influentials considered the seminars were a good medium for communicating this type of information to husbands. There was some initial resistance to some seminars (especially in Sohag), however, because some people were opposed to family planning. Influentials mentioned an overall difficulty reaching men in general, because there is no natural venue that brings men together, apart from religious services.

"This topic (family planning) has become infamous even if good stuff will be discussed in those seminars, people are still not ready to listen ... " (A community leader in Sohag)

"I need a good entry point to discuss the topic with husbands ... I suggest that we call it protecting the health of the family through birth spacing ..." (A community leader in Sohag). 


\section{Impact of the Intervention on Knowledge, Attitudes and Behaviors}

\section{Women's birth spacing attitudes and intentions}

As shown in Table 15, significantly more women in the intervention groups indicated a suitable birth spacing interval would be 3-5 years (difference between group I and control and group II and control was statistically significant). When asked if they would wait for three years before a subsequent pregnancy, slightly more women in the two intervention groups answered that they would, compared to those in the control group (significant difference between group I and control group and between group II and control group). More women in the intervention groups indicated that they would start using family planning by the $40^{\text {th }}$ day postpartum (significant difference between group I and group II, group I and control group and group II and control group).

Women were asked to mention the three conditions for effective use of LAM (i.e. no return of menses, exclusive breastfeeding and first six months postpartum). Knowledge was low overall, although more women in intervention group II than in group I or the control group knew the three conditions $(28.8 \%$ percent versus $14.3 \%$ and $11.9 \%$, with difference between intervention group II and group I and group II and control group).

At four months postpartum, women were asked about the planned time interval before their next pregnancy. This was significantly longer in the two intervention groups than in the control group (difference between the two intervention groups and the control group).

Table 15: Percent distribution of birth spacing attitudes and intentions (by study group)

\begin{tabular}{|l|c|c|c|}
\hline \multicolumn{1}{|c|}{ Views on birth spacing } & $\begin{array}{c}\text { Health services } \\
\text { model intervention }\end{array}$ & $\begin{array}{c}\text { Community } \\
\text { awareness } \\
\text { model }\end{array}$ & Control \\
\hline Suitable birth spacing interval & 550 & 481 & 385 \\
N (exit interview) & 3.3 & 2.1 & 5.2 \\
One year or less & 25.8 & 23.3 & 45.5 \\
Two years & 70.6 & 74.0 & 48.8 \\
Three to five years & 0.4 & 0.6 & 0.5 \\
Six years & & & \\
\hline Birth spacing attitudes & 90.7 & 88.1 & 82.8 \\
Accept to space for at least three years & 94.4 & 87.3 & 79.2 \\
Accept to use FP by day 40 Postpartum & & & \\
\hline Desired waiting time before next pregnancy & 548 & 476 & 385 \\
N at 4 months postpartum & 28.6 & 28.6 & 22.6 \\
Mean (in month) & 479 & 435 & 341 \\
N at 10-12 months postpartum ${ }^{3}$ & 24.8 & 25.9 & 17.1 \\
Mean (in months) & & & \\
\hline
\end{tabular}

${ }^{* * *} p$ less than 0.001

\footnotetext{
${ }^{3}$ Women who were already pregnant at 10-12 months were not asked about desired waiting time
} 
At 10-12 months, one tenth of women in the study were pregnant, with no significant differences between the three groups. Those who were not pregnant were asked how long they were planning to wait before getting pregnant again, and the mean desired waiting time was significantly longer among Model I and Model II women than control group women (no statistically significant difference between the two intervention groups).

\section{Women's birth spacing behavior}

In efforts to achieve the desired birth interval, women were encouraged to take some intermediate steps, such as discussing birth spacing with their husbands, visiting the health facility by the $40^{\text {th }}$ day postpartum, and initiate and continued use of contraception for at least two years postpartum.

Figure 2 shows that significantly more women in the two intervention groups, compared with the control group, reported visiting a health facility at day 40 ( $<0.001$ for difference between two intervention groups and control group). Also, significantly more women in the two intervention groups reported discussing a desired birth interval with their husband.
Figure 2: Percent distribution of interviewed mothers at 4 months PP home visit by selected birth spacing practices

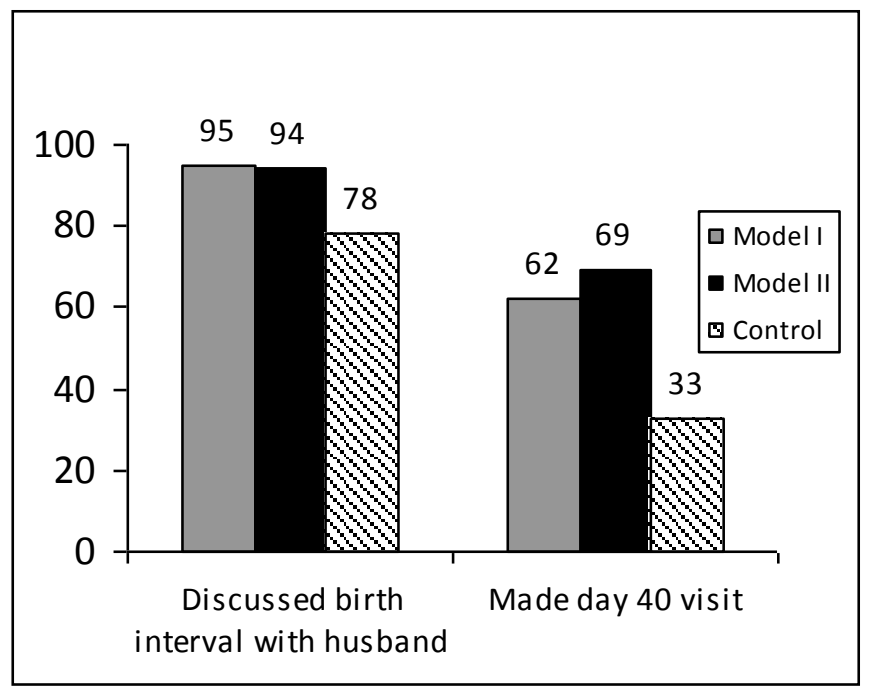

At 4 months postpartum women were asked if they were using any method of contraception. Table 16 shows that significantly more women in Model I than in Model II and the control group were using contraception at four months postpartum. Women who reported using LAM were asked about the criteria for its effective use (Group II mothers were excluded from this analysis because there were only two. Table 16 shows that in group I, more women were aware of the three criteria compared to the control group, but this difference was not statistically significant.

Table 16 : Contraceptive use at 4 months postpartum and knowledge of correct use of LAM (by study group)

\begin{tabular}{|l|c|c|c|}
\hline & $\begin{array}{c}\text { Health } \\
\text { services } \\
\text { model }\end{array}$ & $\begin{array}{c}\text { Community } \\
\text { Awareness } \\
\text { model }\end{array}$ & Control \\
\hline N & $\mathbf{5 5 0}$ & $\mathbf{4 8 1}$ & $\mathbf{3 8 5}$ \\
Percent using contraception & 50.2 & 35.9 & 32.7 \\
$\begin{array}{l}\text { Knowledge of Criteria for LAM use } \\
\text { N used LAM }\end{array}$ & 81 & 2 & 55 \\
\% Know 3 Criteria & 18.8 & - & 7.3 \\
\hline
\end{tabular}


At 10-12 months, women were asked if they were currently using any family planning method. Table 17 shows that significantly more women in group I and group II were using contraception at this time, compared to the control group. It is important to note that the difference between group I and group II was also statistically significant $(\mathrm{p}<0.01)$.

Table 17: Percent distribution of contraceptive use at 10-12 months postpartum (by study group)

\begin{tabular}{|l|c|c|c|}
\hline $\mathbf{N}$ & $\begin{array}{c}\text { Health } \\
\text { services } \\
\text { model }\end{array}$ & $\begin{array}{c}\text { Community } \\
\text { awareness } \\
\text { model }\end{array}$ & Control \\
Contraceptive use & $\mathbf{5 4 6}$ & $\mathbf{4 7 9}$ & $\mathbf{3 8 4}$ \\
Currently using contraception & 42.1 & 33.2 & 25.8 \\
Using contraception (after excluding not at risk) & 47.9 & 42.5 & 30.7 \\
Non use of contraception & & & \\
N did not use during 10 - 12 month period & 256 & 285 & 243 \\
Main reasons for non use: & & & \\
Husband traveling & 24.6 & 36.1 & 22.6 \\
Clean breastfeeding & 39.5 & 43.2 & 28.8 \\
Refusal of husband or mother in law & 27.7 & 15.8 & 25.9 \\
Other & 8.2 & 4.9 & 22.7 \\
\hline
\end{tabular}

Women who reported not using any contraception since delivery were asked why; the three main reasons were: "husband is traveling"; "clean breastfeeding" and "refusal of husband or mother in law". Other reasons mentioned included the fact that women were separated from their husbands, had difficulty becoming pregnant and were afraid of side effects.

The proportion of current FP users at 10-12 months was calculated after excluding women who had indicated that their husband was traveling or that they were separated from their husband, since those two groups were not at risk of getting pregnant. Table 17 shows that the proportion of current FP users at 10-12 months among women at risk of becoming pregnant was significantly higher in the two intervention groups compared to the control group (differences between group I and group II were also statistically significant). It is important to note that some women discontinued FP use during this 10-12 month period (11.0 percent for group I, 7.3 percent for group II and 11.0 percent for control), and others switched contraceptive methods.

Life table analysis was used to measure the duration of protection for women in the three study groups. Women in the intervention groups were protected for a significantly longer period of time, on average, than those in the control group; the median duration of family planning use was 6.8 months for Group I, 4.5 months for Group II and 2.9 months for the control group ( $\mathrm{p}=0.025$ for difference between group I and group II). 


\section{Husbands' knowledge and attitudes}

In the interviews at 4 months and 10-12 months postpartum, women were asked about their husbands' acceptance of the selected birth spacing interval, their current use of contraception and their husband's satisfaction with the method. Table 18 presents these results.

Table 18: Percent distribution of reported husband acceptance of birth spacing by women in the three study groups

\begin{tabular}{|l|c|c|c|}
\hline & Model I & Model II & Control \\
\hline $\mathbf{4}$ month PP visit & & & \\
N & $\mathbf{5 4 8}$ & $\mathbf{4 7 6}$ & $\mathbf{3 8 5}$ \\
\% husband approves of declared interval & 90.5 & 86.1 & 77.9 \\
\hline $\mathbf{1 0 - 1 2}$ month PP visit & & & \\
N & $\mathbf{4 8 3}$ & $\mathbf{4 3 9}$ & $\mathbf{3 4 8}$ \\
\% husband approves of declared interval & 84.5 & 88.8 & 86.8 \\
\hline Husband satisfaction with used FP method & & & \\
N & $\mathbf{2 3 0}$ & $\mathbf{1 5 9}$ & $\mathbf{9 9}$ \\
\% satisfied & 96.5 & 97.5 & 97.0 \\
\hline
\end{tabular}

Source: Women's 4 month and 10-12 month interviews

At 4 months, husbands in both intervention groups were more likely to approve the selected birth interval. However, these differences had disappeared by the 10-12 months interview. Additionally at 10-12 months, husbands in all study groups were equally satisfied with the family planning method used by their wife.

FGDs with husbands revealed some positive effects of the intervention. In model II communities, the majority of husbands mentioned not less than three years as the optimum spacing interval (12 out of 15 in Assiut and 11 out of 17 in Sohag). Of those, the majority specifically mentioned 3-5 years as the optimum birth spacing interval. The majority of husbands agreed to wait for the specified period and found no reason to not practice birth spacing. The majority of husbands also accepted their wife's use of contraception by the $40^{\text {th }}$ day postpartum (32 out of 36).

"This interval is good so the child would grow well and take his time and the mother would be more comfortable .. I don't see any problem with implementing that interval ..." (Male FGD participant in Sohag)

In communities that received Model I, very few husbands mentioned 3-5 years as an optimal birth spacing interval (2 out of 16). The majority of Model I husbands had never heard of the 3-5 year interval (11 out of 16), except for the few who had heard about it on TV or from $R R$ home visits. Attitudes of husbands towards the idea of practicing a birth interval of 3-5 years were positive, however, with a 15 out of 16 in Assiut and 8 out of 16 in Sohag accepting the idea. Two husbands in Sohag expressed concern about effects of contraception on the health of the mother.

"How can I guarantee that she will be able to get pregnant again after 5 years.. I could give her a family planning method that would do her bad things ..." (Male FGD participant from Sohag). 
Concerning the use of contraceptives by the $40^{\text {th }}$ day postpartum, almost all participants in Assiut vocalized approval, while less than half of husbands in Sohag (7 out of 17) approved. The main concern among these husbands who disapproved was potential side-effects from the contraceptive methods.

Additional to the clear differences between husbands' perspectives in Model I and Model II, there were additionally drastic differences in the knowledge and attitudes in the control communities. In both Assiut and Sohag control groups, the majority of husbands mentioned desired birth intervals between one and three years, even though most of these men had heard of the three-to-five year interval. Additionally, husbands in the control communities agreed that women who wanted to space their pregnancies should use a contraceptive method that is prescribed by a physician, yet most men (with the exception of two) strongly believed that contraceptives may cause infertility.

\section{Utilization of health services}

Utilization of services was assessed by comparing the service statistics for health facilities in each group from October to December 2005 (pre-intervention) and March - May 2007 (one year post-intervention) for the total number of FP clients, FP clients with one child, and the number of clients who received prenatal care. Utilization data for each health facility are in Table B4 in Appendix B.

For each study group, the percentage change in utilization between 2005 and 2007 was calculated. As shown in Figure 3, there was an overall increase in number of clients between 2005 and 2007, for all three services and for all three groups. The most notable impact observed was among family planning clients with one child: whereas there was a 3.2 percent increase in the control group, Model I clinics witnessed a 36.0 percent increase and Model II a 47.4 percent increase. Although part of this increase may be due to seasonal differences in the time of data collection, the lack of increase in the control group suggests that these increases are likely to be due to the intervention rather than another factor.

Figure 3: Percentage change in utilization of services at study clinics

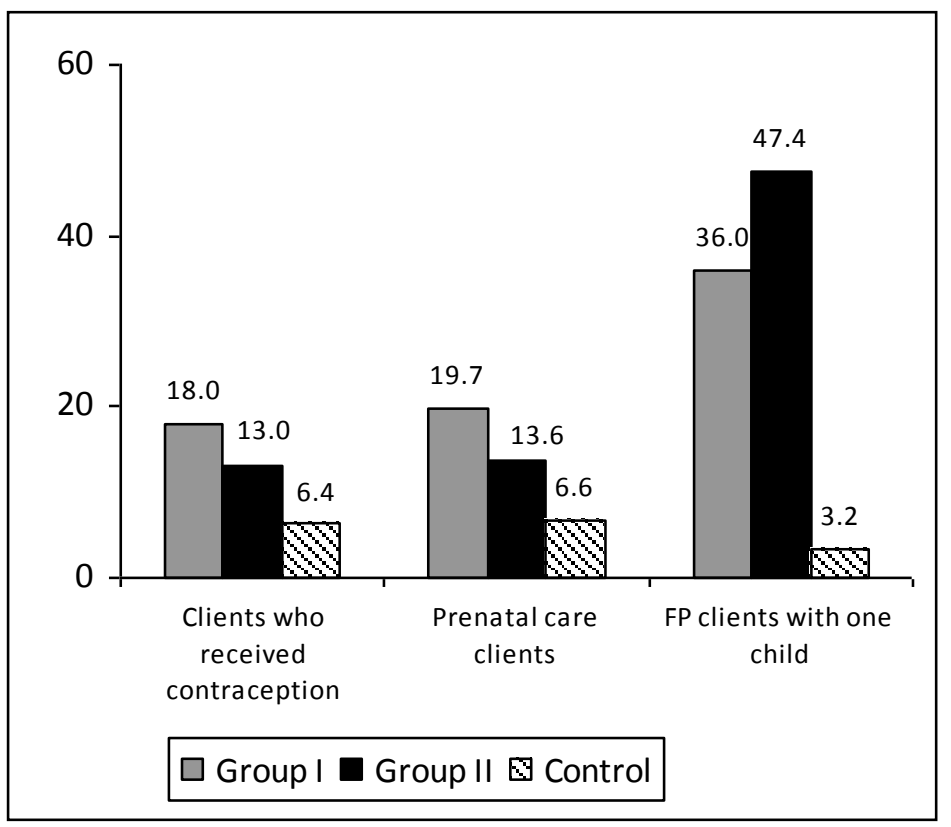




\section{CONCLUSIONS}

The study findings suggest that rural low parity women and men in the governorates of Assiut and Sohag are willing to space their births for at least three years to preserve the health of wife and children. Longer birth intervals (i.e. five years) are not acceptable and should not be promoted by the Egyptian family planning program.

Discussions about birth spacing and postpartum contraception during antenatal care and postpartum home visits were feasible and acceptable to women and to their health care providers. Women viewed this integrated service as a good quality service, and providers believed that integration of $\mathrm{MCH}$ and family planning services helped them work together as a team. However, specific aspects of the integrated care, such as the number of home visits and the content of messages delivered, may need to be revised to avoid redundancy and to maximize effectiveness of visits.

Both models of providing birth spacing messages were effective in changing knowledge and attitudes towards birth spacing. Model I used the health services provide messages to pregnant and postpartum women, and Model II utilized health services plus awareness raising activities among husbands and med. Contraceptive behavior and utilization of family planning services, especially by low parity women, has improved as a result of these interventions, and women exposed to either of the models were more likely than women in the control group to use contraception during the extended postpartum period, and to also use it for longer periods.

Unexpectedly, communities receiving Model I message-delivery fared better in regards to birth spacing attitudes and behaviors, in comparison to those exposed to Model II, the community awareness model. There are several plausible explanations for this difference. Firstly, women exposed to Model I had more years of schooling and were more likely to work for cash compared to those exposed to Model II. Secondly, the intervention appears to have been better implemented in Model I clinics than in Model II clinics, as evidenced by the higher percentage of women in Model I clinics who reported receiving counseling on during prenatal care, advised to use a contraceptive by the $40^{\text {th }}$ day, and visited by $\mathrm{MCH}$ and $R R$.

It should be noted that the community awareness component of this intervention relied mostly on seminars and other forms of interpersonal communication, and did not specifically address husbands of low parity women, but all men in the community. Awareness raising seminars were open to men of all age groups and having any number of children. The seminars were held once a month and attended by 50 to 60 participants. Hence, it is possible that husbands of women interviewed in the study sample did not actually attend those seminars and activities and therefore were not directly affected by the intervention.

It is interesting to note that although contraceptive use reported among women in group II was not higher than in group I, service statistics showed a substantial increase in the proportion of FP clients with one child in Model II clinics. This could be attributed to a gradual gain in momentum of Model II interventions and awareness-raising activities, reaching a larger audience over time and impacting contraceptive use among other (and more) low parity women in the community. 
Finally, although the intervention has been successful in changing the attitudes and behaviors concerning birth spacing, fear of side effects continues to be a concern among women and their husbands and thus interferes with effective and continued use of contraception. Programs promoting birth spacing should include services to help women cope with side-effects and to allay concerns about effects of family planning methods on women's health and subsequent fertility.

\section{POLICY RECOMMENDATIONS}

- Messages on birth spacing and postpartum contraception should be an integral component of antenatal care services for low parity women. Women who come for antenatal care in the third trimester should, at a minimum, receive the following information: advantages of delaying the next pregnancy for 2-3 years, postpartum family planning methods, criteria for effective use of LAM and importance of the 40th day visit.

- The postpartum home visits protocol should be revised to include fewer and more effective visits by the $\mathrm{MCH}$ nurse and $R R$. The $\mathrm{MCH}$ nurse could continue to make three visits (day 2 and day 4 alone and day 7 jointly with the RR) while the RR could make one additional visit on day 21 to promote birth spacing and postpartum use of contraception additional to messages about breastfeeding, personal hygiene and nutrition. The roles of $\mathrm{MCH}$ and $R R$ and messages to be given by each should be clearly defined to avoid duplication and/or redundancy of messages.

- Services provided on the mother's day 40 postpartum visit should be combined with health services for the newborn. This would enhance utilization of both services and save time. It may also be worthwhile to move up the first postpartum family planning visit to the $30^{\text {th }}$ day, and combine it with the first well-baby visit which includes newborn examination, BCG immunization, and health education for the mother, among other things.

- Health providers (physicians, nurses, $R R s$ ) should receive adequate training on the management of contraceptive side-effects. Also, clients who receive family planning methods should be given information that clearly mentions expected side-effects and addresses misconceptions related to their chosen method. This information can also be shared with concerned members of their families.

- A mechanism for providing support to contraceptive users should be developed in order to help them cope with contraceptive side-effects, and possible pressure from husband and mothers-in-law. Quarterly home visits by RRs in the extended postpartum period could serve that purpose.

- The effectiveness of community seminars could be enhanced by selecting good role models as speakers for the seminars and also, embedding birth spacing messages within broader context of family health. Local businessmen or NGOs could assist in making the seminars more attractive to men by providing refreshments or snacks for participants or offering prizes to those who answer questions correctly. 
- Awareness-raising seminars for husbands should be supported by far reaching channels of communication such as mass media, print materials, to recruit optimum number of participants. Seminar messages for men should specifically highlight: (1) the importance of birth spacing for 2-3 years, (2) the religious perspective on birth spacing, (3) the value of the girl child, and (4) the safety of family planning methods.

\section{UTILIZATION OF RESULTS}

The Ministry of Health and Population is the main stakeholder benefiting from these study results. Senior officials of the Maternal and Child Health Sector and the Population and Family Planning Sector have been heavily involved in all phases of the study. Moreover, a representative from each of the two sectors was part of the study team and took part in study activities.

Three steering committees were convened for the project, one at the central level and one in each study governorate. The central committee met every two months, was headed by the two Undersecretaries (MCH and Pop \& FP), and reviewed broader issues like the study's design, results and policy implications. The two governorate committees were headed by the governorate Undersecretary and included Family Planning and $\mathrm{MCH}$ directors, district level directors and IEC officers, $R R$ supervisors and $\mathrm{MCH}$ nurse supervisors. The main role of these committees was to monitor the program's implementation and resolve administrative and logistical issues that interfered with effectively providing the intervention.

Results of the study have been disseminated through a series of publications and dissemination seminars in Egypt and briefing meetings with senior MOHP officials. Three seminars have been held: one in Cairo and one in each of the study governorates. The Cairo seminar was attended by more than 60 participants, including policy makers, program managers, CAs, researchers and representatives from the media. Participants agreed that $\mathrm{MCH}$ and family planning services should be integrated and all opportunities for reaching women with birth spacing messages should be sought. Participants also highlighted the need for community mobilization activities to gauge the interest of men and their involvement in the health of their wives and children. The Cairo seminar was featured by several local newspapers, one being Al-Ahram newspaper (widely read in Egypt and the Arab region). The coverage presented excerpts from the study and stressed the importance of birth spacing for 3-5 years.

The two local seminars were attended by 60-70 participants each. Participants represented MOHP officials at the governorate and district level, senior officials from other ministries, religious leaders, and health care providers from intervention clinics. $\mathrm{MCH}$ and FP supervisors and health care providers commended the intervention, highlighting its impact on increasing utilization of services. They requested that the intervention be scaled up to cover two entire districts per governorate, and also requested to use the training materials for training providers in other districts.

The MOHP has shown keen interest in the results of the study. Birth spacing messages have been incorporated into service delivery protocols for antenatal care. The $R R$ home visits program has been revised to include joint visits with the $\mathrm{MCH}$ nurse and to include integrated messages about 
the health of mother and newborn, birth spacing and postpartum use of contraception. Discussions are underway with MOHP officials to find appropriate mechanisms to enhance effectiveness of the $40^{\text {th }}$ day postpartum visit. One possibility is to link it with services provided to the newborn.

The study results have been used by the TAKAMOL Project, the bilateral USAID-funded project, in updating national guidelines for primary health care. TAKAMOL has used some of the study's policy recommendations, namely the integration of birth spacing messages in antenatal care and joint postpartum home visits by nurse and $R R$. The CHL project has made reprints of the Birth Spacing flier to be distributed to MOHP clinics nationwide. Last but not least, the USAID Mission provided funding to the FRONTIERS Project to build national capacity to enhance correct use of LAM, one of the main mechanism to assist women in achieving desired and optimal birth spacing intervals in Egypt.

\section{REFERENCES}

Abdel-Tawab, Nahla, Hala Youssef, Sarah Loza, Amal Zaki and Salwa Farag. 2006. Helping

Egyptian women achieve optimal birth spacing intervals through maximizing opportunities in antenatal and postpartum care. FRONTIERS Research Update, no. 9. Cairo, Egypt: Population Council.

El-Zanaty F. \& Way, A. 2006. Egypt Demographic and Health Survey., 2005. Cairo, Egypt: Ministry of Health and Population, National Population Council, El-Zanaty and Associates, and ORC Macro.

Loza, Sarah. 2005. Findings of Diagnostic Study for Optimal Birth Spacing Project. Cairo, Egypt: Social Planning, Analysis and Administration Consultants.

Setty- Venugopal, V. and Upadhyay, U.D. 2002. "Birth spacing: Three to five saves lives". Population Reports, Series L, No. 13, Baltimore, Johns Hopkins Bloomberg School of Public Health, Population Information Program.

World Health Organization. 2006. Report of a WHO Technical Consultation on Birth Spacing. Geneva: World Health Organization. 


\section{APPENDICES}

\section{Appendix A}

\section{Birth Spacing Study Antenatal Care Checklist}

\begin{tabular}{|c|c|c|c|c|}
\hline Goverr & Health unit: & Pre & nancy mon & \\
\hline Serial & Health Service & Done & Not done & $\begin{array}{c}\text { Not } \\
\text { applicable }\end{array}$ \\
\hline 1 & Hemoglobin test & & & \\
\hline 2 & Urine sugar test & & & \\
\hline 3 & Albumin test & & & \\
\hline 4 & $\mathrm{RH}$ for primiparas or those who have one child & & & \\
\hline 5 & Asking about the medical history & & & \\
\hline 6 & Measuring blood pressure correctly & & & \\
\hline 7 & Measuring weight correctly & & & \\
\hline 8 & Giving Tetanus vaccination / completing & & & \\
\hline 9 & The medical examination is conducted by the doctor & & & \\
\hline 10 & Education on danger signs & & & \\
\hline 11 & Health education on nutrition & & & \\
\hline 12 & Birth spacing health education in the $3^{\text {rd }}$ trimester & & & \\
\hline 13 & Health education on breast feeding in the $3^{\text {rd }}$ trimester & & & \\
\hline 14 & Advice on how to get prepared for delivery & & & \\
\hline 15 & Postpartum family planning health education & & & \\
\hline 16 & Giving supplements as iron & & & \\
\hline 17 & Recording data in the health card & & & \\
\hline 18 & $\begin{array}{l}\text { Confirming the next follow up date and giving IEC } \\
\text { materials }\end{array}$ & & & \\
\hline 19 & Way of treating the client & Poor & Moderate & Good \\
\hline 20 & $\begin{array}{l}\text { Source of data } \\
\text { 1. Observation } \\
\text { 2. Through meeting the client/service provider } \\
\text { 3. Through records }\end{array}$ & & & \\
\hline
\end{tabular}

The supervisors' remarks and how were dealt with problems:

1.

2.

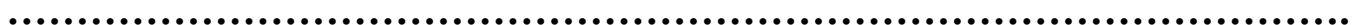

Supervisor's name:

Occupation:
Doctor's /nurse name:

Date of visit: 


\section{Birth Spacing study \\ Postpartum home visit checklist}
Governorate
Health unit $\square$
Date of Visit

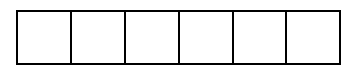
District
Visit number
1
2
3
4
5

Total number of visits received by the mother

Who made the visit

Number of visits

1. The nurse

2. The Raeda

3. Both the nurse and the Raeda

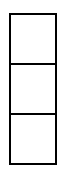

\begin{tabular}{|l|l|l|l|l|}
\hline Serial & Performance & Done & Not done & $\begin{array}{c}\text { Not } \\
\text { Applicabl } \\
\text { e }\end{array}$ \\
\hline Mother Examination: & Measuring Temperature & & \\
\hline 1 & Measuring blood pressure & & & \\
\hline 2 & Asking about vaginal discharge (amount-color-smell) & & & \\
\hline 3 & Breast examination & & & \\
\hline 4 & $\begin{array}{l}\text { Fundus examination (above the umbilicus-between the } \\
\text { umbilicus and the symphysis) }\end{array}$ & & & \\
\hline 5 & Perineal examination (normal-wounds-pus) & & & \\
\hline 6 & Leg veins examination & & & \\
\hline 7 & Infant Examination: & & & \\
\hline 1 & Height-Weight & & & \\
\hline 2 & Umbilicus examination (normal-inflammation) & & & \\
\hline 3 & Neonatal Jaundice examination & & \\
\hline 4 & Asking about: difficulty in breathing-Cyanosis-convulsions & & & \\
\hline 5 & Making sure of the absence of obvious congenital defects & & & \\
\hline 6 & Asking about breast feeding & & & \\
\hline Health Education: & Nutrition Education & & & \\
\hline 1 & Education about personal hygiene & & & \\
\hline 2 & Education about Physical exercise & & & \\
\hline 3 & Education about birth spacing & & & \\
\hline 4 & Education about breast feeding & & & \\
\hline 5 & Education about Thyroid test & & & \\
\hline 6 & Education about vaccination schedule & & & \\
\hline 7 & LAM conditions Education & & & \\
\hline 8 & Family planning counseling & & & \\
\hline 9 & Using IEC materials as: booklets-publications-publications & & & \\
\hline 10 & Giving supplemtent & & & \\
\hline 11 & Letting the woman know the date of the next visit & & & \\
\hline 12 & Confirming date of health unit visit before the 40 \\
(between 30 to 35 days) & & & & \\
\hline 13 & Recording data in the mother and the child health card & & & \\
\hline 14 & & & & \\
\hline
\end{tabular}


The way of treating the client

The way of collecting Data

1. Through meeting the client

2. Observation

3. Records

\begin{tabular}{|l|l|l|}
\hline Poor & Moderate & Good \\
& & \\
& & \\
\hline
\end{tabular}

Supervisor's remarks about the reasons of the shortcomings and how they were dealt with:
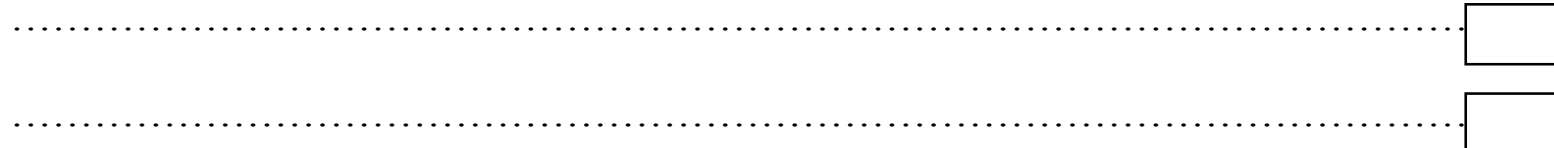

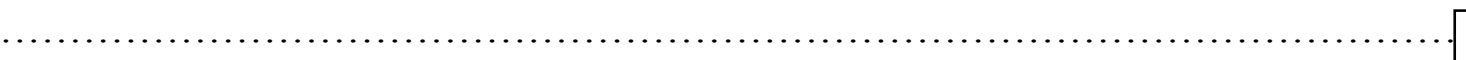

Supervisor's name:

Nurse/Raeda's name:

Occupation: 


\section{Birth Spacing Study}

\section{Day 40 visit checklist}

Governorate: District: Health unit: Date of delivery:

Visit date:

\begin{tabular}{|c|c|c|c|c|}
\hline Serial & Performance & Done & Not done & Not applicable \\
\hline \multicolumn{5}{|c|}{ Mother health services: } \\
\hline 1 & Medical examination by the doctor & & & \\
\hline 2 & Health education on physical exercise & & & \\
\hline 3 & Health education on birth spacing & & & \\
\hline 4 & Health education on breast feeding & & & \\
\hline 5 & LAM health guidance & & & \\
\hline 6 & Health education on nutrition & & & \\
\hline \multicolumn{5}{|c|}{ Infant's health services: } \\
\hline 1 & Height & & & \\
\hline 2 & Weight & & & \\
\hline 3 & Taking the necessary vaccination(BCG) & & & \\
\hline 4 & $\begin{array}{l}\text { Making sure of the absence of obvious } \\
\text { congenital defects }\end{array}$ & & & \\
\hline \multicolumn{5}{|c|}{ Family planning Services: } \\
\hline 1 & Family planning counseling & & & \\
\hline 2 & Provided family planning methods & & & \\
\hline 3 & Type of method: & & & \\
\hline 4 & Directions on how to use the method & & & \\
\hline 5 & Directions on the method's side effects & & & \\
\hline 6 & $\begin{array}{l}\text { Ensuring the date of the follow up visit in case } \\
\text { of obtaining the method }\end{array}$ & & & \\
\hline 7 & Giving the client IEC materials & & & \\
\hline \multicolumn{5}{|c|}{ Recording data in the health card } \\
\hline Way of & treating the client & Poor & Moderate & Good \\
\hline $\begin{array}{c}\text { Source } \\
1 . \\
2 . \\
3 .\end{array}$ & $\begin{array}{l}\text { of data } \\
\text { Observation } \\
\text { Through meeting the client/service provider } \\
\text { Through records }\end{array}$ & & & \\
\hline
\end{tabular}

Supervisors' remarks and how problems were dealt with:

1.

2.

Supervisor's name:

\section{Occupation:}




\section{Appendix B}

Table B1: Characteristics of interviewed community influentials who participated in FGDs

\begin{tabular}{|l|c|c|}
\hline Governorate & Assiut & Sohag \\
\hline N & $\mathbf{1 4}$ & $\mathbf{1 6}$ \\
\hline Age & 25 & 35 \\
Minimum in Years & 58 & 59 \\
Maximum in Years & & \\
\hline Number of Children & 4 & 4 \\
Mean number of children & 1 & 2 \\
Minimum Number & 8 & 7 \\
Highest Number & & \\
\hline Education & - & 1 \\
Preparatory/ intermediate & 14 & 2 \\
Secondary/ Diploma & - & \\
University & & 5 \\
\hline Occupation & 4 & 5 \\
Religious leader & 5 & 2 \\
Health clerk/ sanitarian/ nutritionist & 1 & 2 \\
Manager of youth center/NGO & 1 & - \\
Ag. Ext. worker & 1 & 2 \\
Social worker & 1 & 2 \\
Technician & 1 & \\
Population Educator & & \\
\hline
\end{tabular}


Table B2: Socio-demographic characteristics of husbands who participated in FGDs

\begin{tabular}{|c|c|c|c|}
\hline & Model I & Model II & Control \\
\hline Number of FGDs & 4 & 4 & 4 \\
\hline Number of Participants & 32 & 32 & 32 \\
\hline \multicolumn{4}{|l|}{ Age in Years } \\
\hline Youngest age & 20 & 20 & 21 \\
\hline Oldest age & 47 & 41 & 52 \\
\hline Mean age & 31.3 & 28.8 & 31.0 \\
\hline \multicolumn{4}{|l|}{ Education } \\
\hline Illiterate & 7 & 8 & 8 \\
\hline Read and Write & 1 & 3 & 1 \\
\hline Primary/intermediate & 7 & 6 & 3 \\
\hline Secondary/diploma & 12 & 9 & 18 \\
\hline University & 5 & 6 & 2 \\
\hline \multicolumn{4}{|l|}{ Occupation } \\
\hline Farmer & 5 & 14 & 9 \\
\hline Salaried & 12 & 9 & 8 \\
\hline Worker & 12 & 4 & 7 \\
\hline Trade & 1 & 2 & 1 \\
\hline Skilled Worker & 1 & - & 4 \\
\hline Unemployed & 1 & 3 & 3 \\
\hline \multicolumn{4}{|l|}{ Number of Children } \\
\hline One child & 12 & 13 & 15 \\
\hline Two children & 20 & 18 & 14 \\
\hline Three children & - & 1 & 3 \\
\hline \multicolumn{4}{|l|}{ Age of youngest child } \\
\hline 6 months or less & 14 & 18 & 13 \\
\hline 7-12 months & 18 & 9 & 19 \\
\hline Older than 12 months & - & 4 & - \\
\hline
\end{tabular}


Table B3: Percentage distribution of health providers by suggestions on sustainability of intervention services by occupation and governorate

\begin{tabular}{|c|c|c|c|c|}
\hline \multirow[b]{2}{*}{ Requirements to Ensure Sustainability } & \multicolumn{4}{|c|}{ ASSIUT \& SOHAG } \\
\hline & Phys. & $\begin{array}{c}\text { FP } \\
\text { nurses }\end{array}$ & $\begin{array}{c}\mathrm{MCH} \\
\text { nurses }\end{array}$ & Raidat \\
\hline $\mathbf{N}$ & 35 & 26 & 86 & 39 \\
\hline At the Central Level * & & & & \\
\hline $\begin{array}{l}\% \text { A facilitative and morally supportive system of supervision } \\
\% \text { Expansion to all health units } \\
\% \text { Increase incentives }\end{array}$ & $\begin{array}{c}34 \\
2.9 \\
37.1\end{array}$ & $\begin{array}{c}23 \\
- \\
46.3\end{array}$ & $\begin{array}{c}20 \\
3.5 \\
40.5\end{array}$ & $\begin{array}{c}25 \\
7.7 \\
53.8\end{array}$ \\
\hline$\%$ Increase continuous training & 51.4 & 34.6 & 26.7 & 28.2 \\
\hline $\begin{array}{l}\% \text { Ensure appropriate numbers of nurses, RRs and FP female } \\
\text { physicians }\end{array}$ & 5.7 & 7.9 & 9.4 & 5.1 \\
\hline$\%$ Provide health units for physical facilities Needs & 37.3 & 11.5 & 27.9 & 10.3 \\
\hline $\begin{array}{l}\text { \% Utilization of mass media, seminars \& IEC materials to raise } \\
\text { community awareness }\end{array}$ & 31.4 & 11.5 & 16.6 & 17.9 \\
\hline$\%$ Other needs & 5.7 & 11.5 & 1.2 & 2.6 \\
\hline $\begin{array}{l}\text { At the Directorate Level } \\
\% \text { Increase friendly \& supportive supervision }\end{array}$ & 51.4 & 38.5 & 29.1 & 41 \\
\hline $\begin{array}{l}\% \text { Increase awareness through mass media seminars and IEC } \\
\text { materials }\end{array}$ & 33.7 & 19.2 & 25.2 & 28.2 \\
\hline$\%$ Increase incentives & 14.3 & 0.8 & 17.8 & 23 \\
\hline$\%$ Increase continuous training & 37.1 & 38.5 & 49.9 & 59 \\
\hline$\%$ Meet health unit physical facilities needs & 11.4 & 23.1 & 20.2 & 10.3 \\
\hline$\%$ Well define responsibilities & - & - & 2.3 & 2.5 \\
\hline$\%$ Increase nurses, raidat \& female physicians & 11.4 & 7.7 & 8.1 & - \\
\hline$\%$ Provide transportation facilities for home Visits & 2.9 & 7.7 & 3.5 & 5.1 \\
\hline$\%$ Other needs & - & 3.8 & - & 5.1 \\
\hline $\begin{array}{l}\text { At the District level } \\
\% \text { Provide resources for the Project }\end{array}$ & 17.2 & 34.6 & 34.7 & 15.4 \\
\hline$\%$ Increase nurses and female physicians & 11.4 & 15.4 & 4.8 & 7.7 \\
\hline \% Improved supervision & 65.7 & 46.2 & 57.1 & 51.3 \\
\hline$\%$ Incentives & 11.4 & 15.4 & 15.5 & 23.1 \\
\hline$\%$ Provide continuous guidance & 25.8 & 23.1 & 22 & 15.6 \\
\hline$\%$ Community awareness raising & 20 & 3.8 & 8.3 & 12.8 \\
\hline$\%$ Transportation for home visits & 5.7 & 7.7 & 10.5 & 12.8 \\
\hline \% Support health units to implement Ministry Decisions & - & - & 1.2 & - \\
\hline$\%$ Other & - & 3.8 & - & 7.7 \\
\hline $\begin{array}{l}\text { At the Health Unit Team Level }{ }^{*} \\
\% \text { Work together as coordinated team }\end{array}$ & 77.1 & 73 & 83.7 & 77 \\
\hline \% Support each other for perfection & 14.3 & 11.5 & 7 & 5.1 \\
\hline \% Effectively implement FP and MCH Responsibilities & 14.3 & 19.3 & 14.2 & 12.8 \\
\hline$\%$ Provide needed counseling at the right time & - & - & 2.4 & - \\
\hline$\%$ Organize and increase home visits & 2.9 & - & 4.7 & - \\
\hline$\%$ Inform communities of all that is new & 2.9 & - & 1.2 & 2.5 \\
\hline \% Physicians be more cooperative with mothers, nurses and RR & 5.8 & 11.6 & 2.3 & 23 \\
\hline$\%$ Organize work between them to avoid Differences & 8.6 & 3.8 & 5.8 & 2.5 \\
\hline$\%$ Other & 2.9 & 3.8 & 2.4 & 5.1 \\
\hline
\end{tabular}

*sum of responses may exceed 100 as more than one response was allowed 
Table B4: Number of family planning clients, new prenatal care clients by quarter, by study clinic and governorate

\begin{tabular}{|c|c|c|c|c|c|c|}
\hline & \multicolumn{3}{|c|}{$\begin{array}{l}\text { Number of FP } \\
\text { Clients }\end{array}$} & \multicolumn{3}{|c|}{$\begin{array}{l}\text { Number of New } \\
\text { Prenatal Clients }\end{array}$} \\
\hline & $\begin{array}{l}\text { Oct.- } \\
\text { Dec. } \\
2005\end{array}$ & $\begin{array}{l}\text { Mar.- } \\
\text { May } \\
2006\end{array}$ & $\begin{array}{l}\text { Mar.- } \\
\text { May } \\
2007\end{array}$ & $\begin{array}{l}\text { Oct.- } \\
\text { Dec. } \\
2005\end{array}$ & $\begin{array}{l}\text { Mar.- } \\
\text { May } \\
2006\end{array}$ & $\begin{array}{l}\text { Mar.- } \\
\text { May } \\
2007\end{array}$ \\
\hline \multicolumn{7}{|l|}{ ASSIUT } \\
\hline EXPERIMENTAL VILLAGES & & & & & & \\
\hline El Bora & 223 & 195 & 257 & 22 & 39 & 31 \\
\hline El Hedaya & 195 & 242 & 306 & 41 & 64 & 46 \\
\hline Mesra'a & 196 & 166 & 200 & 45 & 51 & 47 \\
\hline Qorqares & 88 & 110 & 133 & 44 & 26 & 44 \\
\hline Awlad Ibrahim & 269 & 315 & 382 & 51 & 60 & 62 \\
\hline $\begin{array}{l}\text { EXPERIMENTAL \& COMMUNITY VILLAGES (EL } \\
\text { QOUSIA) }\end{array}$ & & & & & & \\
\hline Bouq & 205 & 259 & 259 & 66 & 91 & 86 \\
\hline Bani Zeid & 153 & 200 & 198 & 70 & 140 & 94 \\
\hline El Sheikh Dawoud & 223 & 257 & 272 & 75 & 76 & 80 \\
\hline Bani Idris & 153 & 119 & 125 & 36 & 31 & 31 \\
\hline El Sabha & 93 & 71 & 72 & 20 & 22 & 35 \\
\hline \multicolumn{7}{|l|}{ Control Villages (Abnoub) } \\
\hline Bani Ibrahim & 63 & 60 & 69 & 122 & 109 & 31 \\
\hline Arab El Awamer & 84 & 92 & 81 & 34 & 30 & 35 \\
\hline El Shanabla & 233 & 218 & 219 & 132 & 184 & 174 \\
\hline \multirow{2}{*}{$\begin{array}{l}\text { Kom El Mansoura } \\
\text { Arab El Kadadih }\end{array}$} & 168 & 196 & 246 & 101 & 120 & 118 \\
\hline & 167 & 148 & 155 & 100 & 128 & 107 \\
\hline \multirow{2}{*}{\multicolumn{7}{|c|}{$\begin{array}{l}\text { SOHAG } \\
\text { EXPERIMENTAL VILLAGES }\end{array}$}} \\
\hline & & & & & & \\
\hline El Atamna & 149 & 170 & 167 & 57 & 75 & 83 \\
\hline Salamon & 216 & 234 & 284 & 82 & 82 & 60 \\
\hline El Hamaa & 174 & 207 & 144 & 112 & 175 & 167 \\
\hline Kom El Arab & 146 & 162 & 119 & 39 & 53 & 55 \\
\hline Kom Eshqaw & 131 & 151 & 134 & 44 & 64 & 48 \\
\hline \multicolumn{7}{|l|}{ EXPERIMENTAL \& COMMUNITY VILLAGES } \\
\hline El Haridia El Qebliya & 85 & 73 & 148 & 25 & 38 & 35 \\
\hline Benho & 297 & 331 & 347 & 48 & 67 & 76 \\
\hline Nogoua El Sawamaa & 180 & 162 & 178 & 64 & 108 & 118 \\
\hline Benga & 286 & 253 & 284 & 145 & 121 & 83 \\
\hline Bani Harb & 98 & 113 & 146 & 47 & 41 & 39 \\
\hline \multicolumn{7}{|l|}{ Control Villages } \\
\hline El Mezawla & 180 & 141 & 124 & 25 & 37 & 32 \\
\hline El Qaraqra & 107 & 133 & 113 & 45 & 34 & 36 \\
\hline El Hamideya & 164 & 152 & 201 & 47 & 41 & 44 \\
\hline El Suth & 65 & 66 & 73 & 39 & 39 & 31 \\
\hline Demno & 99 & 98 & 109 & 42 & 38 & 34 \\
\hline
\end{tabular}


Table B5: Number and characteristics of family planning clients by yearly quarters by study clinic and governorate

\begin{tabular}{|c|c|c|c|c|c|c|c|c|c|c|}
\hline & \multicolumn{5}{|c|}{ Oct. - Dec. 2005} & \multicolumn{5}{|c|}{ March - May 2007} \\
\hline & $\begin{array}{l}\text { Total } \\
\mathbf{N}\end{array}$ & $\begin{array}{c}\% \\
\text { with } \\
\text { no } \\
\text { child }\end{array}$ & $\begin{array}{c}\% \\
\text { with } \\
1 \\
\text { child }\end{array}$ & $\begin{array}{c}\% \\
\text { with } 2 \\
\text { child- } \\
\text { ren } \\
\end{array}$ & $\begin{array}{c}\% \\
\text { received } \\
\text { contra- } \\
\text { ceptives }\end{array}$ & $\begin{array}{l}\text { Total } \\
\mathbf{N}\end{array}$ & $\begin{array}{c}\% \\
\text { with } \\
\text { no } \\
\text { child }\end{array}$ & $\begin{array}{c}\% \\
\text { with } \\
1 \\
\text { child }\end{array}$ & $\begin{array}{c}\% \\
\text { with } 2 \\
\text { child- } \\
\text { ren }\end{array}$ & $\begin{array}{c}\% \\
\text { received } \\
\text { contra- } \\
\text { ceptives }\end{array}$ \\
\hline ASSIUT & & $\%$ & $\%$ & $\%$ & $\%$ & & $\%$ & $\%$ & $\%$ & $\%$ \\
\hline Experimental Villages & & & & & & & & & & \\
\hline El Bora & 223 & - & 11.2 & 26.5 & 11.2 & 257 & - & 21.0 & 26.7 & 21.0 \\
\hline El Hedaya & 195 & - & 10.8 & 24.1 & 10.8 & 306 & - & 20.3 & 27.3 & 20.3 \\
\hline Mesra’a & 196 & - & 11.7 & 16.3 & 11.7 & 200 & - & 10.2 & 28.3 & 10.2 \\
\hline Qorqares & 88 & - & 12.5 & 19.3 & 12.5 & 133 & - & 14.6 & 20.0 & 14.6 \\
\hline Awlad Ioranım & 269 & - & 17.5 & 21.6 & 17.5 & 382 & 0.95 & 18.1 & 32.1 & 18.0 \\
\hline $\begin{array}{l}\text { Experimental \& } \\
\text { Community Villages }\end{array}$ & & & & & & & & & & \\
\hline Bouq & 205 & 6.3 & 6.3 & 11.2 & 6.3 & 259 & - & 5.8 & 10.8 & 5.8 \\
\hline Bani Zeid & 153 & 4.9 & 4.9 & 16.3 & 4.6 & 198 & - & 8.0 & 15.5 & 8.0 \\
\hline El Sheikh Dawoud & 223 & 17.9 & 17.9 & 14.8 & 17.9 & 272 & - & 13.2 & 16.7 & 13.2 \\
\hline Bani Idris & 153 & 7.2 & 7.2 & 18.3 & 7.2 & 125 & - & 21.0 & 25.2 & 21.0 \\
\hline El Sabha & 93 & 10.7 & 10.7 & 8.6 & 10.7 & 72 & - & 2.8 & 15.5 & 2.8 \\
\hline Control Villages & & & & & & & & & & \\
\hline Bani Ibrahim & 63 & - & 4.8 & 12.7 & 4.8 & 69 & - & 6.7 & 15.0 & 6.7 \\
\hline Arab El Awamer & 84 & - & 5.9 & 16.7 & 5.9 & 81 & - & 8.7 & 17.4 & 8.7 \\
\hline Arab El Shanabla & 233 & - & 3.9 & 10.7 & 3.9 & 219 & - & 5.5 & 20.2 & 5.5 \\
\hline Kom El Mansoura & 168 & - & 2.4 & 10.7 & 2.4 & 246 & - & 5.6 & 22.5 & 5.6 \\
\hline Li riciamt & 167 & - & 7.8 & 9.0 & 7.8 & 155 & - & 6.8 & 9.5 & 6.8 \\
\hline SOHAG & & $\%$ & $\%$ & $\%$ & $\%$ & & $\%$ & $\%$ & $\%$ & $\%$ \\
\hline Experimental Villages & & & & & & & & & & \\
\hline El Atamna & 149 & - & 1.3 & 9.4 & 1.3 & 167 & - & 2.4 & 11.8 & 2.4 \\
\hline Salamon & 216 & - & 12.0 & 21.3 & 12.0 & 284 & - & 20.5 & 38.9 & 20.5 \\
\hline El Hamaa & 174 & 1.7 & 11.5 & 17.8 & 11.5 & 144 & - & 2.9 & 7.7 & 2.9 \\
\hline Kom El Arab & 146 & - & 4.8 & 8.9 & 4.8 & 119 & - & 6.2 & 9.3 & 6.2 \\
\hline Kom Eshqaw & 131 & - & 5.3 & 9.2 & 5.3 & 134 & - & 6.0 & 10.6 & 6.0 \\
\hline $\begin{array}{l}\text { Experimental \& } \\
\text { Community Village }\end{array}$ & & & & & & & & & & \\
\hline El Haridia El Qebliya & 85 & - & 3.5 & 17.6 & 3.5 & 148 & - & 34.3 & 41.1 & 34.3 \\
\hline Benho & 297 & - & 6.7 & 15.8 & 6.7 & 347 & - & 6.7 & 21.8 & 6.7 \\
\hline Nogou El Sawamei & 180 & - & 2.2 & 8.9 & 2.2 & 178 & - & 4.3 & 14.8 & 4.3 \\
\hline Benga & 286 & - & 8.7 & 13.6 & 8.7 & 284 & - & 14.6 & 21.7 & 14.6 \\
\hline & 98 & - & 4.1 & 13.3 & 4.1 & 146 & - & 16.8 & 15.9 & 16.8 \\
\hline Control Villages & & & & & & & & & & \\
\hline El Mezawla & 180 & - & 11.7 & 32.8 & 11.7 & 124 & - & 9.9 & 27.7 & 9.9 \\
\hline El Qaraqra & 107 & - & 24.3 & 14.0 & 24.3 & 113 & - & 11.3 & 15.8 & 11.3 \\
\hline El Hamadeya & 164 & - & 12.2 & 14.0 & 12.2 & 201 & - & 19.7 & 24.3 & 19.7 \\
\hline El Suteh & 65 & - & 10.8 & 9.2 & 10.8 & 73 & - & 13.6 & 16.7 & 13.6 \\
\hline Demno & 99 & - & 16.2 & 13.1 & 16.2 & 109 & - & 15.3 & 18.4 & 15.3 \\
\hline
\end{tabular}


Table B6: Total number of clients for October - December 2005, March - May 2006 and March - May 2007 by study group and type of service

\begin{tabular}{|l|c|c|c|}
\hline & $\begin{array}{c}\text { Oct - Dec. } \\
\mathbf{2 0 0 5}\end{array}$ & $\begin{array}{c}\text { March - May } \\
\mathbf{2 0 0 6}\end{array}$ & $\begin{array}{c}\text { March - May } \\
\mathbf{2 0 0 7}\end{array}$ \\
\hline Prenatal care clients & $\mathbf{N}$ & $\mathbf{N}$ & $\mathbf{N}$ \\
Model I clinics & 537 & 689 & 643 \\
Model II clinics & 596 & 735 & 677 \\
Control clinics & 687 & 760 & 642 \\
\hline Clients received contraception & & & \\
Model I clinics & 1749 & 1907 & 2077 \\
Model II clinics & 1737 & 1800 & 1962 \\
Control clinics & 1272 & 1260 & 1353 \\
\hline FP clients with one child & & & \\
Model I clinics & 189 & 214 & 257 \\
Model II clinics & 137 & 107 & 202 \\
Control clinics & 124 & 121 & 128 \\
\hline
\end{tabular}

